\title{
REVIEW
}

\section{The emerging role of zinc transporters in cellular homeostasis and cancer}

\author{
Elizabeth Bafaro ${ }^{1}$, Yuting Liu $^{1}$, Yan $\mathrm{Xu}^{2}$ and Robert E Dempski ${ }^{1}$
}

\begin{abstract}
Zinc is an essential micronutrient that plays a role in the structural or enzymatic functions of many cellular proteins. Cellular zinc homeostasis involves the opposing action of two families of metal transporters: the ZnT (SLC30) family that functions to reduce cytoplasmic zinc concentrations and the ZIP (SLC39) family that functions to increase cytoplasmic zinc concentrations. Fluctuations in intracellular zinc levels mediated by these transporter families affect signaling pathways involved in normal cell development, growth, differentiation and death. Consequently, changes in zinc transporter localization and function resulting in zinc dyshomeostasis have pathophysiological effects. Zinc dyshomeostasis has been implicated in the progression of cancer. Here we review recent progress toward understanding the structural basis for zinc transport by ZnT and ZIP family proteins, as well as highlight the roles of zinc as a signaling molecule in physiological conditions and in various cancers. As zinc is emerging as an important signaling molecule in the development and progression of cancer, the ZnT and ZIP transporters that regulate cellular zinc homeostasis are promising candidates for targeted cancer therapy.
\end{abstract}

Signal Transduction and Targeted Therapy (2017) 2, e17029; doi:10.1038/sigtrans.2017.29; published online 28 July 2017

\section{INTRODUCTION}

Zinc is the second most abundant transition metal in the human body. Within a cell, zinc is redox-inert and has a valence state of +2 . Zinc is maintained in the $\mathrm{Zn}^{2+}$ state under all biologically relevant redox potentials and $\mathrm{pH}$ conditions. ${ }^{1}$ Zinc shows flexible and dynamic coordination geometry with nitrogen, oxygen and sulfur ligands present in histidine, glutamate, aspartate and cysteine residues in proteins. ${ }^{1}$ Thus, the chemical properties of zinc are ideal for its many biological roles.

The essentiality of zinc as a trace nutrient was first discovered in the fungus Aspergillus niger in 1869, but it was nearly a century later that zinc was found to be an essential micronutrient for humans. ${ }^{2,3}$ Zinc deficiency is a global public health problem, leaving $\sim 2$ billion people at risk for deficiency of this trace metal. ${ }^{4}$ Human zinc deficiency causes a myriad of symptoms, including diarrhea, alopecia, immune system impairment, chronic inflammation, compromised physical growth and development, neurological deficits and impaired reproductive development. ${ }^{5-7}$ In addition to its important role in normal human physiology, zinc has been associated with pathophysiological conditions, including cardiovascular disease, depression, neurodegenerative diseases such as Alzheimer's disease, diabetes mellitus and cancer. ${ }^{8}$ Consistent with its multifaceted roles in human health and disease, zinc has a number of biological functions at the cellular level. Since it was first discovered as a component of the erythrocyte enzyme carbonic anhydrase in 1939, zinc has been identified as a cofactor in over 300 enzymes spanning all enzyme classes. ${ }^{9,10}$ Equally, zinc is found as a structural component of proteins, and it has been estimated that $~ 3000$ proteins, or $10 \%$ of the human proteome, are zinc containing. ${ }^{11}$ Zinc also serves as a signaling molecule that mediates a number of cellular signal transduction processes. ${ }^{12}$
In this review, we will provide an overview of zinc homeostasis in humans, emphasizing the role of zinc transporters and recent developments in the elucidation of their structures. The role of zinc as a signaling molecule will be discussed. In addition, we will examine the interplay of zinc transporters and zinc signaling pathways in several cancer types.

\section{ZINC HOMEOSTASIS}

The human body contains about $2 \mathrm{~g}$ of zinc, of which only $0.1 \%$ is present in plasma and the remainder is present within the cells. ${ }^{13}$ In mammalian cells, zinc is in one of two forms: protein-bound zinc, which includes zinc both tightly and loosely bound to proteins; and free zinc ions, which are likely not free but are bound by unknown (non-protein) ligands. ${ }^{14-16}$ The free zinc concentration in mammalian cells, while in the picomolar range, likely represents a physiologically significant source of zinc, particularly regarding its role in signaling. ${ }^{16}$ The diverse forms of zinc in the cell make it difficult to assess accurately the intracellular distribution of zinc. Early macro-analytical studies with fractionated rat liver cells, as well as more recent measurements using inductively coupled plasma mass spectrometry on fractionated human lung adenocarcinoma cells, reported that $30-40 \%$ of total intracellular zinc is found in the nucleus, $50 \%$ of zinc is in the cytoplasm and the remaining $10-20 \%$ is membrane-associated. ${ }^{17}$ Nuclear zinc, which is tightly bound to proteins, constitutes the permanently bound zinc pool and is unlikely to be detectable by fluorescent indicators, which measure chelatable, or loosely bound, zinc. ${ }^{18,19}$ Using a fluorescent indicator and organellespecific dyes, Lu et al. ${ }^{19}$ demonstrated that free or transiently bound zinc is found in the endoplasmic reticulum (ER), Golgi apparatus and mitochondria. Newer micro-analytical techniques 
Table 1. Human $\mathrm{ZnT}$ proteins

\begin{tabular}{|c|c|c|}
\hline Protein & Major location of protein expression & Subcellular localization \\
\hline ZnT1 & Ubiquitous & Plasma membrane ${ }^{22}$ \\
\hline ZnT2 & Mammary gland, pancreas, prostate, retina, intestine, kidney ${ }^{23-27}$ & Endosome, lysosome, secretory vesicle, plasma membrane ${ }^{23,24}$ \\
\hline ZnT3 & Brain, pancreas, testis ${ }^{28,29}$ & Synaptic vesicles ${ }^{30}$ \\
\hline ZnT4 & Mammary gland, placenta, prostate, kidney, brain ${ }^{25,26,31-34}$ & Endosome, secretory vesicle, plasma membrane ${ }^{26,31}$ \\
\hline ZnT5 & Heart, placenta, prostate, ovary, testis, intestine, thymus, bone $25,32,35$ & Golgi, vesicles, plasma membrane ${ }^{36}$ \\
\hline ZnT6 & Brain, lung, intestine ${ }^{34,37}$ & Golgi, vesicles ${ }^{37}$ \\
\hline ZnT7 & Intestine, stomach, pancreas, prostate, placenta, testis, retina, muscle ${ }^{25,32,38}$ & Golgi, vesicles ${ }^{38}$ \\
\hline ZnT8 & Pancreas, adrenal gland, thyroid, testis ${ }^{39,40}$ & Secretory granule ${ }^{39}$ \\
\hline ZnT9 & Brain, muscle, kidney ${ }^{41}$ & $\mathrm{ER}^{41}$ \\
\hline ZnT10 & Brain, retina, liver ${ }^{42}$ & Golgi, plasma membrane ${ }^{42}$ \\
\hline
\end{tabular}

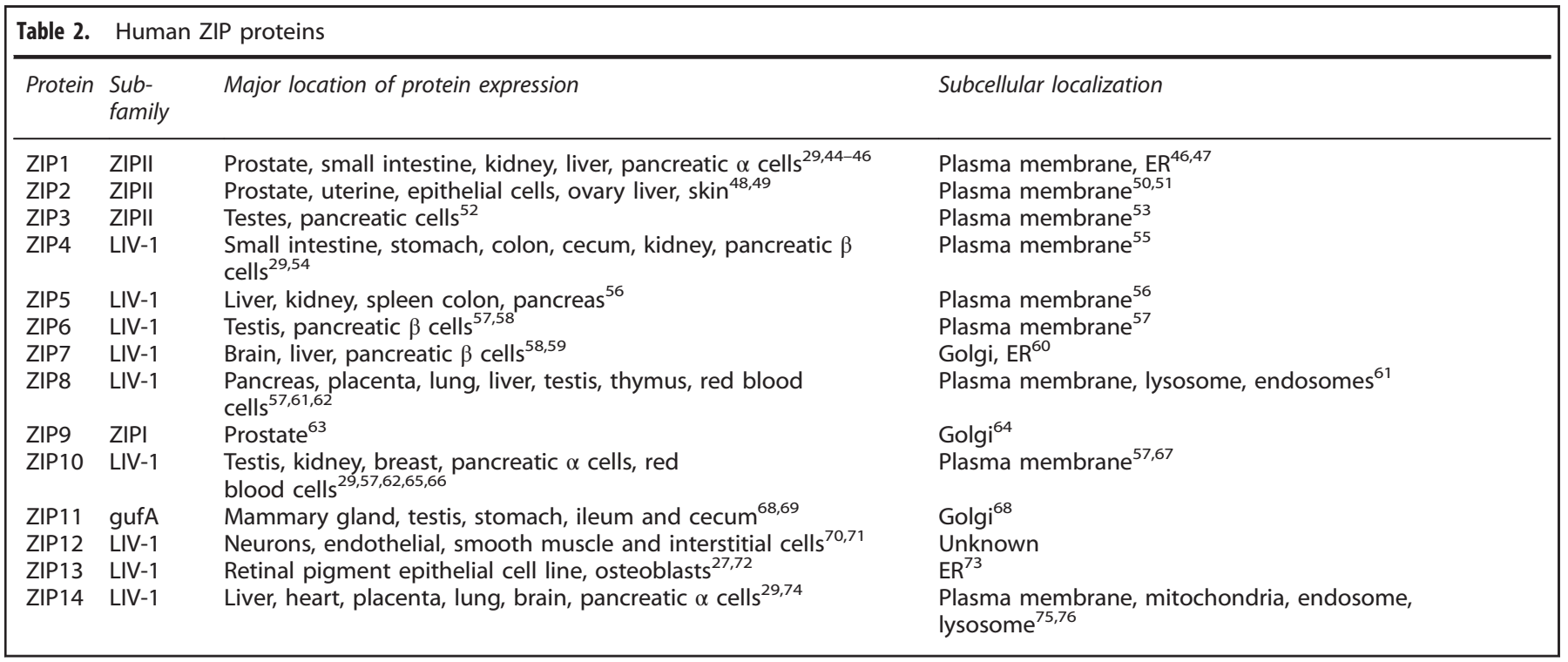

employing synchrotron X-ray fluorescence chemical imaging allow detection of both loosely and tightly bound metals with high spatial resolution and have demonstrated zinc pools in the nucleus, mitochondria and vesicles. ${ }^{20,21}$ This intracellular compartmentalization of zinc is one of the mechanisms by which cells maintain zinc homeostasis and zinc regulates cellular functions. Cellular zinc homeostasis, both total intracellular zinc and compartmentalized zinc, is tightly controlled by the concerted action of proteins that transport, sense, store and release zinc.

\section{Zinc transport}

Zinc transporters responsible for maintaining cytosolic zinc concentrations, as well as zinc levels in cellular compartments, belong to two solute carrier families, SLC30 and SLC39. The human SLC30, or ZnT, family comprises 10 members (Table 1) that function to decrease the cytosolic concentration of zinc by transporting zinc from the cytosol to the extracellular space or into intracellular compartments. ZnT1 is the only SLC30 member that is ubiquitously expressed on the plasma membrane and, consequently, plays an important role in regulating cellular zinc homeostasis. $^{22}$ Consistent with its essential role, homozygous Znt1 knockout mice are embryonically lethal. ${ }^{43}$ The human SLC39, or ZIP (Zrt-, Irt-like proteins), family comprises 14 members (Table 2) that function to increase the cytosolic concentration of zinc by transporting zinc into the cytosol from the extracellular space or from intracellular compartments. Currently, there is no direct structural information available for any full-length, human ZnT or ZIP transporter. However, the X-ray crystal and cryoelectron microscopy structures of a bacterial ZnT homolog, YiiP, as well as a structural model of the human ZIP4 and structural information on the extracellular and intracellular domains of ZIP4 provide valuable mechanistic insight into zinc transport by these two families. $^{77-82}$

X-ray crystal and cryoelectron microscopy structures of the bacterial ZnT homolog YiiP, a proton:zinc antiporter, reveal an alternating access mechanism for zinc transport. YiiP functions as a physiological homodimer, and each protomer consists of six transmembrane (TM) helices, with TMs 1, 2, 4 and 5 forming a helical bundle (Figure 1). ${ }^{77-79}$ Within the helical bundle, a zinc ion is tetrahedrally coordinated by three highly conserved aspartic acid residues and one highly conserved histidine in TM2 and TM5. ${ }^{77}$ Mutagenesis experiments demonstrated the important role of this conserved DD-HD zinc-binding site for transport function and metal selectivity. ${ }^{77,83,84}$ The YiiP structures differ in the orientation of the helical bundle with the cryo-EM structure representing the inward-facing conformation and the X-ray crystal structure representing the outward-facing conformation of the transporter. ${ }^{77-79}$ Conformational switching is due to reorientation of TM5 that is triggered by zinc binding. ${ }^{85}$ The bacterial YiiP structures provide a model for zinc transport by mammalian ZnT proteins. Mammalian ZnTs are predicted to function as metal: proton exchangers, are predicted to have six TM helices and have a signature metal-binding site in TM2 and TM5, similar to the DD$\mathrm{HD}$ site in the bacterial proteins. ${ }^{86,87}$ The HD-HD motif is responsible for the zinc specificity of $\mathrm{ZnTs}$, as the bacterial DD- 
a

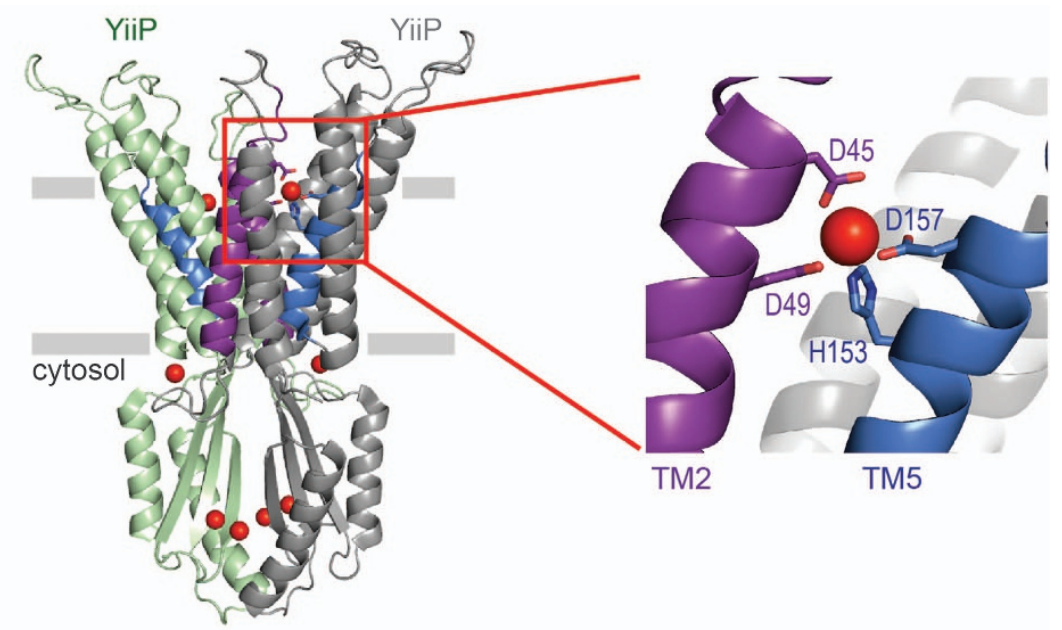

b

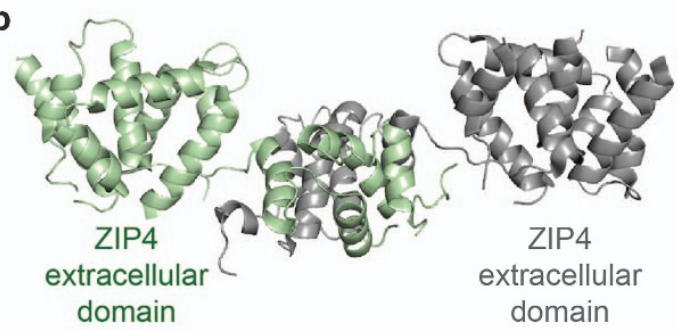

C

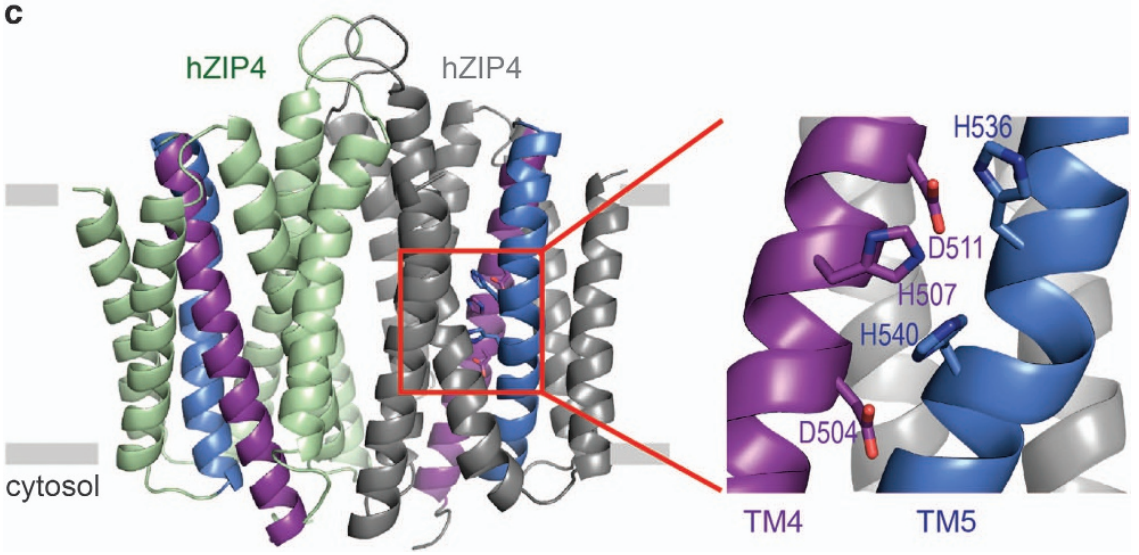

Figure 1. Structural basis for zinc transport by ZnT and ZIP proteins. (a) Crystal structure of bacterial ZnT homolog showing zinc (red spheres) bound in the intracellular domain, the membrane interface and TM domain. TM2 (purple) and TM5 (blue) are involved in zinc ion

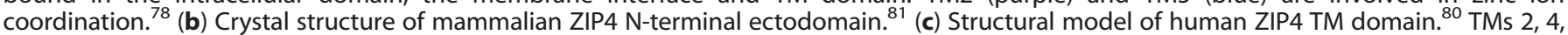
5 and 7 are located in the center of each monomer, and TM4 (purple) and TM5 (blue) contain conserved histidine and aspartic acid residues predicted to coordinate zinc.

HD site allows for zinc and cadmium transport and the ND-HD site in $\mathrm{ZnT10}$ confers manganese specificity. ${ }^{84,88}$

In addition to the TM domain with its zinc coordination site, the bacterial YiiP structures have two large C-terminal intracellular domains (one from each protomer), which, along with two intracellular loops, establish the primary dimerization contact. ${ }^{77,78}$ Human ZnTs are similarly predicted to have large C-terminal cytoplasmic domains, and the C-terminal domain is involved in dimerization for human ZnTs. ${ }^{89} \mathrm{ZnT3}$ and ZnT4 form homodimers via covalent bonds between two tyrosine residues (Y357 and Y372 in $\mathrm{ZnT3})$ in their C-terminal domains, and a $\mathrm{YX}(\mathrm{XX})(\mathrm{E} / \mathrm{D})$ motif is likely required for dimerization. ${ }^{89}$ Human $\mathrm{ZnT1}-5$, all of which possess the $Y X(X X)(E / D)$ motif, form homodimers; whereas ZnT6, which has several $\mathrm{C}$-terminal tyrosine residues but lacks the $\mathrm{YX}$ $(\mathrm{XX})(\mathrm{E} / \mathrm{D})$ motif, only forms a heterodimer with $\mathrm{ZnT5}$. $^{89-92} \mathrm{ZnT1-4}$ are also capable of forming heterodimers. ${ }^{91} \mathrm{ZnT}$ dimerization is likely required for proper targeting of the transporter to its cellular location and for zinc transport activity. ${ }^{89}$ Molecular modeling of human ZnT3 based on the bacterial structures revealed that dimerization via dityrosine bond formation generates zinc-binding sites that create a putative zinc translocation pathway through the protein. ${ }^{89}$ In the bacterial YiiP structure, a binuclear zinc-binding site was observed in the C-terminal domain and has coordinating ligands contributed by both protomers. ${ }^{77,78}$ The similarity between the YiiP intracellular domain and the $\beta a \beta \beta a \beta$ metallochaperone-like fold suggests that the cytoplasmic domain of ZnTs may be involved in protein-mediated metal transfer. ${ }^{77,93}$ A third zinc-binding site was identified in the YiiP intracellular loop between TM4 and TM5 and may be involved in transfer of the zinc ion to the membrane zinc-binding site or may function in zinc sensing. ${ }^{77,78}$ 
Compared to ZnTs, less structural and biochemical information is known about the ZIP family of metal transporters. ZIP family members show a higher diversity, compared to the ZnT family, with respect to metal specificity, transport of zinc, iron, manganese, copper and cadmium. ${ }^{80,94-96}$ The energy source for metal translocation by ZIP proteins, while not driven by ATP hydrolysis, remains elusive, and several driving forces, including bicarbonate, $\mathrm{pH}$ dependence or phosphorylation, have been proposed. ${ }^{48,95-98}$ Further, a bacterial ZIP protein reconstituted in proteoliposomes was shown to mediate non-saturable and electrogenic zinc flux, suggestive of zinc channel activity. ${ }^{99}$ This observation led Lin et al. ${ }^{99}$ to speculate that ZIP proteins may function as channels, rather than transporters, and the downhill concentration gradient driving zinc influx into the cytosol through ZIP channels is sustained by cellular homeostasis.

The 14 human ZIP family members are classified into four subfamilies (Table 2): ZIPI (with members ZIP1, ZIP2 and ZIP3), ZIPII (with member ZIP9), gufA (with member ZIP11) and LIV-1 (with members ZIP4-8, ZIP10 and ZIP12-14). ${ }^{50}$ All ZIP members are predicted to have eight TM segments, and members of the LIV-I family, with the exception of ZIP13, are predicted to have a large, extracytosolic N-terminal domain. Recently, the $\mathrm{N}$-terminal domain of a ZIP4 protein was solved using X-ray crystallography. Human ZIP4 is expressed in the gastrointestinal tract on the apical surface of enterocytes and as such is the major zinc transporter responsible for the uptake of dietary zinc. Mutations in ZIP4 cause the inherited zinc deficiency disease acrodermatitis enteropathica (AE). ${ }^{55,100} \mathrm{AE}$ mutations affect the expression, trafficking, uptake activity or posttranslational processing of ZIP4, and a number of these mutations map to the $\mathrm{N}$-terminal extracellular domain. ${ }^{101-103}$ The $\mathrm{N}$-terminal domain is posttranslationally cleaved during extended periods of zinc starvation. ${ }^{102}$ The crystal structure of the black fruit bat ZIP4 extracellular domain revealed a homodimer with two subdomains (Figure 1). ${ }^{81}$ The dimer core, comprising the C-terminal subdomain, forms two helix-turn-helix folds and contains the PAL sequence that is highly conserved among the LIV-1 subfamily. ${ }^{81}$ The second subdomain, comprising the N-terminal residues, has a unique a-helical fold. ${ }^{81}$ Both subdomains were shown to be required for optimal zinc transport activity. The subdomains are connected by a disordered linker region that is important for proper folding and trafficking of the full-length ZIP4 protein, as well as for zinc transport. ${ }^{81}$ Analysis of the N-terminal ectodomains of the other LIV-1 family members revealed that the dimerization subdomain is conserved, with the exception of ZIP7 and ZIP13. ${ }^{81}$ The ZIP7 and ZIP13 ectodomain sequences are the most divergent among SLC39 members, and the oligomerization status of the ZIP7 and ZIP13 ectodomains is unknown. As the full-length ZIP7 and ZIP13 proteins form homodimers in the membrane, oligomerization of SLC39 proteins is not mediated exclusively by their ectodomains. ${ }^{73,98}$ The ZIP5 ectodomain has also been purified and shown to be homodimeric. $^{104}$ Interestingly, ZIP5, as well as ZIP6 and ZIP10, colocalize with the prion protein. ${ }^{104,105}$ An evolutionary link between ZIP ectodomains and the prion protein has been suggested but the functional and structural significance remains to be elucidated. ${ }^{106}$ It has been hypothesized that the extracellular domains of ZIP proteins may act as extracellular zinc sensors. ${ }^{81}$

Although to date, there is no crystallographic or cryo-EM structural data that encompasses the membrane domain for any ZIP protein, a computational model of the human ZIP4 protein provides clues as to how ZIP proteins function. Using co-evolution contact predictions and Rosetta $a b$ initio structure prediction, structural models of the TM domain of ZIP4 were generated (Figure 1). ${ }^{80}$ The models exhibit eight TM helices with TMs 2, 4, 5 and 7 forming a helical bundle that contains a putative metal permeation pathway. ${ }^{80}$ The putative ZIP4 metal permeation pathway is lined with highly conserved histidine and aspartic acid residues, analogous to the transmembrane zinc-binding site
(DD-HD) observed in the crystal structure of the ZnT homolog YiiP (Figure 1). ${ }^{77,80}$ In support of the model's proposed zinc translocation pathway, the transport kinetics and metal specificity of ZIP4 are altered upon mutagenesis of the conserved histidine residues H507 in TM4 and H536, the first histidine in the conserved HEXXH motif in TM5. ${ }^{80}$ Equally, ZIP8 and ZIP14 have a variation of the HEXXH motif (EEXXH), wherein the glutamic acid substitution is believed to contribute to the broader metal specificity of these SLC39 members. ${ }^{107}$ In generating the ZIP4 structural models, the contact predictions could only be satisfied when ZIP4 was modeled as a dimer with TM helices forming the dimer interface. ${ }^{80}$ Evidence for homodimerization of other ZIP proteins, including ZIP2, ZIP7 and ZIP13, as well as a heteromer of ZIP6 and ZIP10 supports the ZIP4 dimer model. ${ }^{73,98,108,109}$

The ZIP4 structural modeling did not include the large cytoplasmic loop between TMs 3 and 4, which is predicted to be present in all ZIP family members. Studies with the ZIP4 protein have shown that its plasma membrane surface expression is regulated by the cytoplasmic loop in a zinc-dependent fashion. As cytosolic zinc concentrations increase (low micromolar), ZIP4 undergoes endocytosis. ${ }^{110}$ At higher cytosolic zinc concentrations $(\sim 20 \mu \mathrm{M})$, ZIP4 is ubiquitinated at a conserved lysine residue located on the TM3-TM4 loop and is subjected to proteasomal degradation. ${ }^{111}$ Further studies using the purified protein region have confirmed that the loop directly binds two zinc ions sequentially. ${ }^{82}$ The first zinc is tightly coordinated by a $\mathrm{CysHis}_{3}$ site, and the second zinc ion binds with lower affinity to a histidine-only site. ${ }^{82}$ The TM3-TM4 loop is an intrinsically disordered region (IDR) that remains disordered upon zinc binding. ${ }^{82}$ The structural flexibility of intrinsically disordered proteins and IDRs provides a functional advantage by permitting multiple posttranslational modifications, such as phosphorylation and ubiquitination, and interactions with multiple protein partners or ligands. ${ }^{112,113}$ Disordered protein regions tend not to be under strong evolutionary conservation. ${ }^{114}$ Unsurprisingly, the length and amino-acid sequence of the TM3-TM4 loop is not conserved among ZIP proteins, but all contain a variable number of potential zinc-coordinating residues histidine, cysteine, aspartate and glutamate. Accordingly, the large cytoplasmic loop of ZIP transporters likely functions as a protein-specific regulatory region that senses and responds to cytosolic zinc concentrations. The specific protein(s) or ligand(s) interacting with this region have yet to be identified and are likely to be important for our further understanding of ZIP structure-function relationship.

\section{Intracellular zinc sensing}

The metal-response element-binding transcription factor (MTF-1) regulates expression of its target genes in a zinc-dependent manner and thus acts as a cellular zinc sensor. ${ }^{115,116}$ MTF-1 interacts with metal-response element (MRE) sequences in the promoters of zinc-regulated genes. ${ }^{116}$ MTF-1 contains six $\mathrm{Cys}_{2}-\mathrm{His}_{2}$ zinc fingers and three transcriptional activation domains. ${ }^{116}$ In response to zinc, MTF-1 is translocated to the nucleus, where it interacts with MREs and activates transcription of its target genes. ${ }^{115,116}$ Transcription of genes encoding metallothioneins and the zinc efflux transporters $\mathrm{ZnT1}$ and $\mathrm{ZnT2}$ are activated by MTF-1 in response to zinc. ${ }^{24,115,116}$ Recently, the zincresponsiveness of the human transcriptome was examined when MTF-1 was knocked down relative to normal levels. ${ }^{117}$ Surprisingly, almost 200 genes are differentially expressed in response to zinc when MTF-1 is silenced. ${ }^{117}$ This observation suggests the presence of multiple levels of zinc sensing within the cell, with MTF-1 acting as the master zinc sensor that controls intracellular zinc concentrations via direct effects on gene expression of zinc transporters and metallothioneins. ${ }^{117}$ 
Zinc storage and release

Metallothioneins are small, cysteine-rich, metal-binding proteins that maintain metal homeostasis by acting as metallochaperones. Metallothioneins have been shown to act as metal donors and acceptors for metal-containing enzymes and transcription factors. ${ }^{18,119}$ Humans possess four metallothionein isoforms (MT1, MT2, MT3 and MT4) that can maximally bind seven zinc ions via tetrahedral coordination to cysteine residues. The seven zinc ions have been shown, based on structural data, to cluster into two domains, the $\mathrm{N}$-terminal $\beta$-domain containing three metal ions and the C-terminal a-domain containing four metal ions. Each zinc-binding site possesses an independent zincbinding affinity. ${ }^{120}$ Thus, metallothioneins are capable of buffering zinc under physiological conditions and controlling the storage and release of intracellular zinc.

\section{ZINC SIGNALING}

In addition to its structural and functional roles in proteins, zinc acts as a signaling molecule within cells. Early evidence showing zinc-dependent regulatory effects on protein tyrosine phosphatases and transcription factors pointed to the role of zinc in intracellular signaling pathways. ${ }^{121,122}$ However, the work of Yamasaki et al. ${ }^{123}$ a decade ago established zinc as a second messenger, whereby changes in its intracellular concentration are directly altered by an external stimulus and relayed to an intracellular signaling axis. Using mast cells, Yamasaki et al. ${ }^{123}$ demonstrated that, upon extracellular stimulation of the $\lg \mathrm{E}$ receptor, zinc is rapidly released into the cytosol from an intracellular store likely originating from the perinuclear and ER regions. The released zinc, termed the 'zinc wave', activates two mitogen-activated protein kinase (MAPK) pathways, the extracellular signal-related kinase (ERK) and the c-Jun N-terminal kinase (JNK). MAPKs, such as ERK and JNK, are serine/threonine protein kinases that, upon activation by extracellular or intracellular signals, phosphorylate proteins involved in regulating cell proliferation, differentiation and apoptosis. ${ }^{124}$ In addition to activating MAPK signaling cascades, the intracellular zinc released in the mast cell cytosol inhibits protein tyrosine phosphatase activity. ${ }^{123}$ Protein tyrosine phosphatases, which dephosphorylate tyrosine residues, are involved in many cell signaling cascades, including the integrin and cadherin signaling pathways that control cell adhesion and motility. ${ }^{125}$ The inhibition of protein tyrosine phosphatases by zinc ions occurs at picomolar concentrations of zinc, consistent with cytoplasmic fluctuations of free zinc levels. ${ }^{126}$ Tyrosine phosphorylation via protein tyrosine kinases is also a key component of the cytoplasmic accumulation of zinc that occurred in leukocytes treated with the extracellular stimulus lipopoylsaccharide. ${ }^{127}$ Lipopolysaccharide produces a rapid increase in cytosolic zinc in mammalian leukocytes, and the zinc wave influences signaling pathways involving MAPKs and the transcription factor NF-KB, which targets genes involved in cellular development, growth and apoptosis. ${ }^{18}$

The zinc wave induced by extracellular stimuli in both mast cells and leukocytes occurred rapidly (within minutes) and originated from intracellular zinc stores. ${ }^{123,127}$ This phenomenon has been termed 'early' zinc signaling. ${ }^{128}$ In addition to its role as a second messenger in 'early' zinc signaling events, zinc has been shown to participate in 'late' signaling events that occur hours after stimulation and involve zinc transporters. ${ }^{128}$ One such 'late' signaling event was observed during the embryonic development of zebrafish, during which signal transducer and activator of transcription (STAT) proteins are active. ${ }^{129}$ STAT proteins are activated via a signal transduction pathway that is stimulated by extracellular binding of cytokines or growth factors to a receptor. Once activated, STAT proteins transcriptionally regulate a number of genes. In the zebrafish, STAT3 was shown to stimulate transcription of the zinc importer ZIP6. The STAT3-dependent ZIP6 expression results in downstream activation of the transcriptional repressor Snail, which is involved in the epithelial to mesenchymal transition (EMT) in embryonic development. ${ }^{129,130}$ Although the function of ZIP6 in zinc uptake during zebrafish embryonic development was not demonstrated, this study provided the first evidence showing a metal homeostatic mechanism (ZIP6 transporter) is regulated by signal transduction (STAT signaling), and the altered cellular metal homeostasis signals changes in cellular processes. Expression of the zinc exporter ZnT2 has also been shown to be regulated by a STAT signaling pathway, and $\mathrm{ZnT2}$ transcription is stimulated by STAT5. ${ }^{24,131}$

Another zinc transporter, ZIP14, was shown to be involved in a G-protein-coupled receptor (GPCR) CAMP signaling pathway using ZIP14 knockout mice, which displayed growth defects. ${ }^{132}$ The growth defects observed in the ZIP14-deletion mice resulted from inactivation of the parathyroid hormone-related peptide (PTHrP) signaling pathway that involves CAMP. PTHrP activates adenylyl cyclase, which increases cAMP levels. cAMP then stimulates protein kinase $A(P K A)$, resulting in PKA translocation to the nucleus and activation of the CAMP response element-binding (CREB) transcription factor by phosphorylation. Phosphorylated CREB ( $p$-CREB) promotes transcription of $c-f o s$, another transcription factor whose target genes are involved in cell differentiation, proliferation, survival and EMT. This signaling pathway is disrupted in the ZIP14 knockout mice, which show decreased nuclear translocation of PKA, a downregulation of $p$-CREB and lower CAMP levels. ${ }^{132}$ The decreased levels of cAMP are due, not to a decrease in the hormone PTHrP, but to increased activity of phosphodiesterase (PDE). PDEs are known regulators of GPCR signaling pathways. Significantly lower intracellular zinc levels were measured in growth plates from the ZIP14 knockout mice than in ZIP14-expressing mice, demonstrating that ZIP14 is required for zinc uptake and establishing a link between zinc and GPCR/CAMPdependent signaling cascades. ${ }^{132}$

Expanding the list of signaling cascades influenced by zinc, cellular zinc status directly affects the activity of the STAT pathway. ${ }^{133}$ STAT proteins regulate the expression of genes involved in cell proliferation, differentiation, survival and apoptosis. $^{134}$ The STAT signaling pathway begins with an extracellular signal that activates the Janus tyrosine kinase, which then activates STAT proteins by phosphorylation. Phosphorylated STAT proteins are translocated to the nucleus where downstream signals are regulated transcriptionally. Levels of phosphorylated STAT1 and STAT3 are 40-50\% lower, and corresponding nuclear levels of these STAT proteins are lower, in fetal rat brains upon maternal zinc deficiency compared to the zinc-adequate controls. ${ }^{133}$ Equally, cytosolic zinc accumulation in lactating ZnT2 knockout mice resulted in a significant reduction in phosphorylated STAT5 levels, but not total STAT5 levels, compared to mice expressing ZnT2. ${ }^{135}$ As zinc has been shown to influence many phosphorylation-dependent signaling cascades (for example, MAPKs, protein tyrosine phosphatases and transcription factors) that play important roles in cell development, proliferation and cell death, proper maintenance of cellular zinc homeostasis is critical. The dysregulation of cellular zinc homeostasis and its detrimental effects on intracellular signaling have many pathophysiological consequences.

Compared to the best-studied metal second messenger calcium, a more comprehensive picture of zinc cellular signaling remains elusive. Technological advancement in zinc measurement and regulation, as well as more systematic signaling studies are critical in making progress in these areas. In the following section, the consequences of zinc dyshomeostasis on zinc signaling in cancer will be discussed. 


\section{ZINC TRANSPORTERS AND ZINC SIGNALING IN CANCER}

Cellular zinc homeostasis is altered in cancer. Zinc levels in serum are typically decreased in patients with tumors, including breast, head and neck, lung, liver, prostate, pancreatic and gynecological tumors, compared to normal serum levels. ${ }^{136}$ However, while serum zinc levels are low in most cancers, studies measuring zinc levels in tumor and/or tumor peripheral tissues in different solid cancer types are inconsistent, reporting elevated, decreased or no change in zinc levels when compared with the corresponding normal tissues. ${ }^{136}$ Although the mechanism and effects of zinc dyshomeostasis on cancer initiation and progression are not fully defined, some studies have reported changes in zinc transporter status and effects of altered zinc levels on signaling pathways in tumor tissues and cancer cell lines. The most extensive studies on zinc homeostasis and zinc signaling in cancer have focused on pancreatic, prostate and breast tumors.

\section{Pancreatic cancer}

The pancreas, a gland adjacent to the stomach, has two distinct functionalities as an endocrine and an exocrine gland, and proper pancreatic function requires physiological zinc homeostatic mechanisms. As an endocrine gland, the pancreatic islet cells, which include $a, \beta$ and $\delta$ cells, contribute to blood glucose levels and insulin production. The a cells secrete the hormone glucagon to control hypoglycemia, and zinc acts as a signaling molecule for glucagon secretion. The zinc importers ZIP1, ZIP10 and ZIP14 are expressed on the plasma membrane of pancreatic a cells. ${ }^{29}$ Pancreatic $\beta$ cells produce a zinc:insulin complex that is stored in zinc-rich secretory granules. ${ }^{39}$ ZIP4 is expressed on the plasma membrane of pancreatic $\beta$ cells, suggesting that ZIP4 contributes to maintaining adequate zinc levels in the $\beta$ cells for insulin secretion. ${ }^{29}$ ZIP6 and ZIP7 have also been shown to be expressed in human $\beta$ cells. ${ }^{58}$ Decreasing the expression level of ZIP6 and ZIP7 changed the uptake of zinc into $\beta$ cells and decreased insulin secretion. In addition, the zinc exporter ZnT8 transports zinc into the $\beta$-cell granules, providing zinc for the zinc:insulin complex. ${ }^{39}$ As an exocrine gland, pancreatic acinar cells generate digestive enzymes, many of which are zinc-dependent, in zymogen granules. The SLC30 member ZnT2 transports zinc from the cytosol into the zymogen granules. ${ }^{24}$ The zinc importer ZIP5 is expressed on the plasma membrane of the acinar cells. ${ }^{137}$

Pancreatic cancer is ranked as the fourth leading cause of death due to cancer, and one- and five-year survival rates are 20 and $7 \%$, respectively. Dysregulation of cellular zinc homeostasis has been implicated in the progression of pancreatic cancer. Early studies identified increased mRNA levels of the zinc transporter ZIP4 in 16 of 17 human pancreatic adenocarcinoma samples compared to normal pancreatic tissue. ${ }^{138}$ Equally, in mouse models, ZIP4expressing xenografts yield larger tumors and increased cell proliferation compared to negative controls. ${ }^{138}$ ZIP4 localizes to the basolateral membrane of pancreatic $\beta$ cells, and its upregulation in pancreatic tumors would presumably increase cellular zinc levels. ${ }^{138,139}$ However, using zinc-sensitive histochemical staining, Costello et al. ${ }^{140}$ measured lower zinc levels in human pancreatic cancer tissues spanning early to late malignant stages compared to normal tissues. Concurrent with the decreased zinc levels, ZIP3 is downregulated in the pancreatic cancer tissues, but ZIP4 levels were not quantified. ${ }^{140}$ In a comparative study of the mRNA levels of all ZIP and ZnT transporters in human pancreatic cancer and normal tissues, all ZIP proteins are downregulated in the cancer tissues with the exception of ZIP4, which is upregulated. ${ }^{141}$ Similarly, gene expression levels for all ZnT transporters are lower or unchanged in the pancreatic cancer tumors compared to normal tissues. ${ }^{141}$ Although the data are consistent with the previously observed downregulation of ZIP3 and upregulation of ZIP4, it is difficult to reconcile how increases in zinc transporter mRNA levels result in the decreased cellular zinc levels observed in pancreatic cancer tissues. It should be noted that, to date, there has been no comprehensive study comparing cellular zinc concentrations and zinc transporter expression in the same tissue samples. High variability in zinc transporter expression has been observed in different pancreatic cancer tissues and cell lines. ${ }^{141}$ Equally, mRNA levels and protein expression do not necessarily correlate as many zinc transporters, including ZIP4, are regulated by posttranslational mechanisms. ${ }^{142}$ Moreover, as ZIP4 has been shown to transport other metals, including iron and copper, it remains to be determined whether the observed increase in ZIP4 expression in pancreatic cancer alters cellular zinc concentrations or alters the cellular homeostasis of another metal. ${ }^{80,94}$ For example, serum copper levels are higher in patients with pancreatic cancer, and copper has been shown to have tumorpromoting activity in cells. ${ }^{143-146}$

\section{Prostate cancer}

The human prostate gland contains exceptionally high levels of zinc $(\sim 800-1500 \mu \mathrm{M}$ in prostate epithelial cells compared to $\sim 100-500 \mu \mathrm{M}$ in other soft tissue cells), and the zinc concentration in prostatic fluid is about 500 -fold greater than in plasma. ${ }^{147}$ Also, the mitochondrial zinc level in prostate cells is higher than in other cell types. ${ }^{147}$ Zinc accumulation in prostate epithelial cells is responsible for their unique metabolic and energetic status as 'citrate producing', 'low respiring' cells. ${ }^{147}$ Zinc disrupts both the Kreb's cycle, by inhibiting $m$-aconitase, which converts citrate to cis-aconitate resulting in citrate accumulation, and mitochondrial electron transport, likely via inhibition of cytochrome $c$ reductase. Zinc accumulation in prostate epithelial cells is attributed to the expression of ZIP1, which is present on the basolateral membrane and functions as the major importer of zinc from circulating blood plasma into prostate cells. ${ }^{44,148}$ In addition to ZIP1, ZIP2 and ZIP3 have been identified on the apical surface of normal prostate cells, and it is speculated that these proteins function in the reuptake of zinc from the prostatic fluid. ${ }^{149}$

Compared with normal or nonmalignant prostate tissue, malignant prostate tissue displays markedly lower levels of zinc, and the decline in zinc occurs early in the malignant transformation. ${ }^{150}$ Concomitant with the declining zinc levels, ZIP1 gene expression is downregulated in prostate cancer. ${ }^{151}$ Other ZIP family members, ZIP2, ZIP3 and ZIP4, also show reduced expression in prostate cancer cells. ${ }^{149,152}$ In addition, ZIP3 localizes to lysosomal membranes in a prostate cancer cell line compared to its plasma membrane localization in normal cells. ${ }^{148}$ Changes in the expression levels of the zinc efflux transporters ZnTs during prostate tumorigenesis are ambiguous. ZnT1 expression has been reported to be decreased, increased or unchanged, ZnT4 is decreased or unchanged, ZnT10 is increased and ZnT5 and ZnT6 are decreased in prostate cancer tissues and cell lines compared to normal or nonmalignant prostate tissue. ${ }^{153-157}$ Although it is unclear what role ZnTs play in prostate cancer, the important role of ZIP1 in normal prostate epithelial cells and in prostate cancer development led to the designation of ZIP1 as a tumor suppressor gene in the prostate gland. ${ }^{150}$ As prostate cancer cell lines constitutively express ZIP1, as well as other zinc transporters, it is hypothesized that the downregulation of zinc transporters in malignant prostate tissue is due to epigenetic silencing. ${ }^{150}$

The reduced zinc levels in prostate tumors caused by decreased ZIP transporter expression alter intracellular zinc signaling pathways leading to tumor-promoting activities. Zinc status affects signaling via the Akt protein (protein kinase B) in malignant prostate cells (Figure 2). ${ }^{158}$ Zinc-deficient prostate cancer cells accumulate phosphorylated Akt ( $p$-Akt) due to the absence of the phosphatase and tensin homolog (PTEN) protein. PTEN is known to be inactivated by genomic deletion or rearrangements in the early stages of prostate cancer oncogenesis. ${ }^{159,160}$ Normally, PTEN negatively regulates phosphoinositide 3-kinase (PI3K) activity. In 


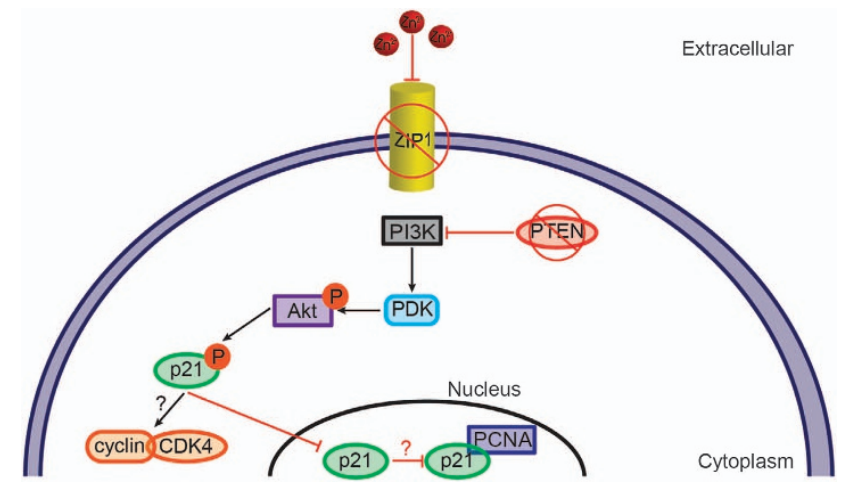

Figure 2. Zinc deficiency in prostate cancer cells promotes cell survival via a phosphoinositide 3-kinase (PI3K) signaling pathway. Prostate cancer cells lack ZIP1 and PTEN. In zinc-deficient, PTENdeficient conditions, $\mathrm{PI} 3 \mathrm{~K}$ is stimulated, leading to phosphorylation of protein kinase $B$ (Akt) via phosphoinositide-dependent kinase (PDK). p-Akt then phosphorylates the cyclin-dependent kinase inhibitor p21. Phosphorylated p21 is retained in the cytoplasm where it may affect the cell cycle activity of the cyclin D/cyclindependent kinase 4 (CDK4) complex. In addition, the lack of nuclear p21 may prevent activation of the PCNA, which normally prevents DNA synthesis during cell cycle progression. Thus, zinc deficiency affects p21 signaling pathways, leading to cell proliferation in prostate cancer cells.

the absence of PTEN, PI3K phosphorylates Akt, and p-Akt subsequently phosphorylates the cyclin-dependent kinase inhibitor p21. ${ }^{158}$ Phosphorylated p21 is retained in the cytoplasm, affecting cell cycle regulation likely due to downstream effects on the cyclin D/cyclin-dependent kinase 4 (CDK4) complex and the proliferating cell nuclear antigen (PCNA). Thus, an Akt-p21 signaling pathway promotes cell proliferation in prostate cancer cells, and this pathway depends on the absence of the zinc transporter ZIP1 and PTEN. PTEN also interacts with MTF-1, linking PTEN activity to the regulation of MTF-1 target genes, such as metallothioneins. ${ }^{161}$ Metallothioneins, particularly MT1 and MT2, are downregulated in prostate cancer tissues compared to normal prostate tissue. ${ }^{162,163}$ Moreover, the levels of metallothionein in human prostate cancer tissue inversely correlate with prostate cancer relapse. ${ }^{163}$ Accordingly, prostate cancer exhibits a complex network linking cellular zinc homeostatic mechanisms, including zinc transporters and metallothioneins, to signaling pathways that promote tumorigenesis.

\section{Breast cancer}

The cellular zinc homeostatic mechanisms in the normal human mammary gland are not known precisely, and much of what is known has been elucidated from human models or mouse studies. ${ }^{164}$ Zinc plays an important role in normal mammary gland growth and development and during lactation and post-lactation transformations (as reviewed by McCormick et al.). ${ }^{164}$ Normal mammary epithelial cells express ZIP5 at the cell surface where ZIP5 is likely involved in metal uptake. ${ }^{164}$ Other ZIP proteins, including ZIP3, ZIP7, ZIP11, ZIP12 and ZIP14, are expressed within intracellular compartments. ${ }^{68} \mathrm{ZnT2}$ also plays an important role in mitochondrial zinc transport during normal mammary gland development. ${ }^{165}$ During lactation, the mammary gland hyperaccumulates zinc, particularly in the Golgi apparatus and the secretory system, to meet increased cellular needs and for secretion into breast milk. ${ }^{166}$ ZIP5, ZIP8 and ZIP10 may be involved in zinc uptake from plasma during lactation. ${ }^{68}$ Interestingly, ZIP7, which exports zinc from the Golgi apparatus and ER, is more highly expressed during lactation, suggesting that the zinc accumulated in the Golgi apparatus is remobilized to the cytosol during lactation. ${ }^{68} \mathrm{ZnT} 4$ is also located on the Golgi apparatus and has been suggested to contribute to zinc export into breast milk. ${ }^{31}$ Zinc secretion into breast milk requires $\mathrm{ZnT2}$, which localizes both to the endosomal/secretory vesicles and to the plasma membrane. ${ }^{23}$ Mutations in $\mathrm{ZnT2}$ cause the disorder transient neonatal zinc deficiency, confirming its essential role in zinc secretion into breast milk. ${ }^{33,167}$ ZIP3 may function in reuptake of zinc from breast milk. ${ }^{168}$ Finally, post-lactational changes in the mammary gland involve both lysosomal-mediated cell death and mitochondrial-mediated apoptosis. ${ }^{164}$ The zinc requirements for these processes may rely on changes in ZnT2, ZnT4 or ZIP8 localization as these proteins have been shown to localize to lysosomal compartments in other cell types. ${ }^{31,164,169,170}$ Given the importance of zinc homeostasis in the mammary gland, it has been suggested that nutritional zinc status may be a risk factor for breast cancer. ${ }^{164,171}$ In support of this, the incidence of mammary tumors in primiparous mice exposed to a carcinogen is lower in mice fed a zinc adequate diet than in mice fed a marginally zincdeficient diet, similar to the zinc-deficient diets often consumed by humans. ${ }^{172}$

In contrast to most solid tumors, breast cancer tissues show significantly higher zinc levels compared with normal breast tissue. ${ }^{136,173-176}$ Zinc distribution and zinc transporter levels show distinct profiles in breast cancer subtypes. ${ }^{142}$ Breast cancer is classified into basal (or triple negative), human epidermal growth factor receptor 2 (HER2) overexpression and luminal (or estrogen receptor positive, ER+) A (low-grade) and B (high-grade) tumors. Using X-ray fluorescence microscopy, Chandler et al. ${ }^{142}$ observed high zinc accumulation around the margins of luminal tumors, whereas basal tumors show uniform distribution of zinc. Breast tumor tissues were analyzed for gene expression of metallothioneins and zinc transporters (ZIP and ZnT). Compared to luminal $(E R+)$ and HER2 overexpression tumors, basal breast cancer tumors expressed higher levels of metallothioneins, ZIP4 and ZIP14 genes and lower levels of ZIP6, ZIP9 and ZIP11. ${ }^{142}$ Luminal breast cancer tumors express higher levels of the ZIP6 gene compared to basal and HER2 overexpression tumors, and ZIP8 gene expression is greater in high-grade versus low-grade ER+ tumors. ${ }^{142}$ Similarly, gene and protein expression profiles for zinc transporters have been assessed in luminal and basal breast cancer cell lines. Kagara et al. ${ }^{66}$ observed higher gene expression of ZIP10 in basal cells and higher gene expression of ZIP6 in luminal cells. At the protein level, basal cells display higher levels of ZnT1, ZIP1 and ZIP10 compared to normal cells; luminal cells display higher levels of all ZnT proteins ZIP3, ZIP5, ZIP6, ZIP8 and ZIP10. ${ }^{142}$ It has been suggested that the differing zinc transporter profiles and their effects on cellular zinc homeostasis may contribute to the phenotypic differences, including invasiveness, metastasis and treatment effectiveness, in breast cancer subtypes. $^{142}$

ZIP10 and ZIP6 have been linked to tumor migration in both basal and luminal breast cancers. ${ }^{6,109,177}$ In basal breast cancer cells, ZIP10 functions as a zinc importer, and ZIP10-mediated zinc uptake stimulates cell migration. ${ }^{66}$ Similarly, in luminal breast cancer cells, ZIP10 promotes cell migration. ${ }^{109}$ Further, in luminal breast cancer cells, ZIP10 has been shown to form a heteromer with ZIP6. ${ }^{109}$ In both ZIP10- and ZIP6-expressing luminal breast cancer cells, the glycogen synthase kinase signaling pathway is inhibited, leading to activation of the Snail transcription factor that represses genes for cell adhesion and promotes EMT (Figure 3). ${ }^{109,177}$ ZIP6, whose gene expression is induced by STAT3 and in the absence of ZIP10, was observed to undergo cleavage of its N-terminal domain, which alters its cellular localization from the ER to the plasma membrane. ${ }^{109,177}$ As both ZIP6 and ZIP10, along with ZIP5, have a prion-like ectodomain, these data suggest a relationship between this subclass of LIV-1 transporters and breast cancer metastasis.

The most common treatment for luminal (ER+) breast cancers is the anti-estrogen drug tamoxifen. However, almost all patients 
a

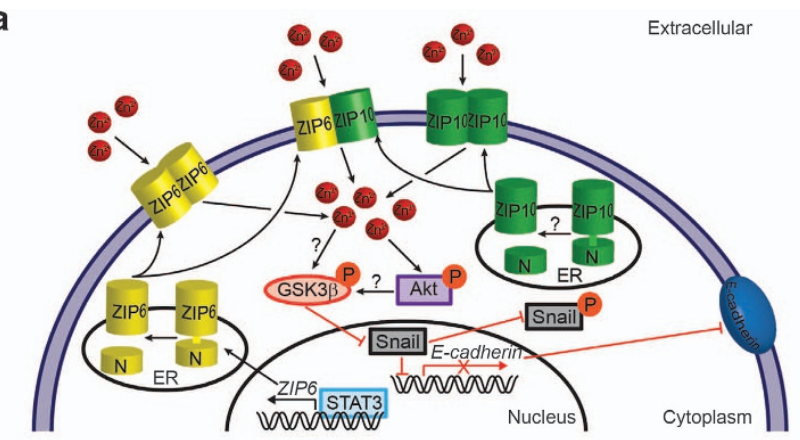

b

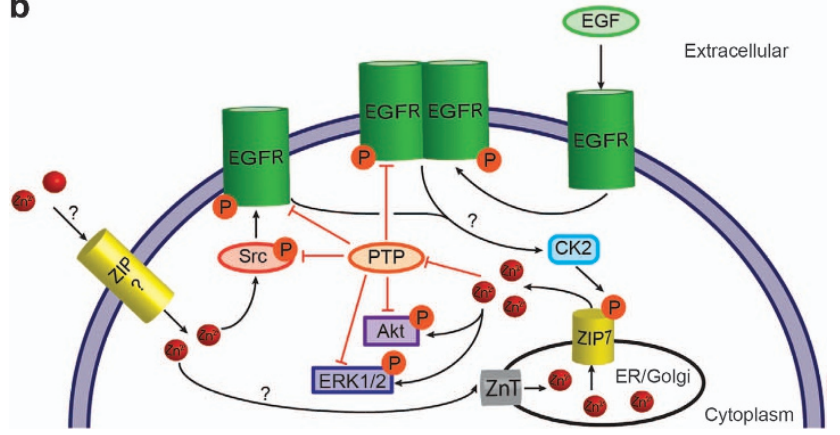

Figure 3. ZIP-mediated signaling pathways promote cell proliferation and metastasis in luminal and tamoxifen-resistant breast cancer cells. (a) ZIP6/ZIP10-mediated signaling pathway in luminal breast cancer cells. ZIP6, whose gene expression is induced by STAT3, is expressed on the ER membrane. On cleavage of its $\mathrm{N}$-terminal domain, ZIP6 translocates to the plasma membrane. ZIP10 may undergo the same posttranslational processing leading to plasma membrane localization. On the plasma membrane, ZIP6 and ZIP10 exist as homo- and heteromers. Zinc uptake via ZIP6 and/or ZIP10 results in the inactivation of glycogen synthase kinase-3 $\beta$ (GSK3 $\beta$ ) by phosphorylation either directly or indirectly by activation (phosphorylation) of Akt. Inactive GSK3 $\beta$ is unable to phosphorylate the transcription factor Snail, resulting in nuclear retention of Snail. Snail represses transcription of the adhesion molecule E-cadherin, leading to cell migration and metastasis. (b) ZIP7-mediated signaling pathway in tamoxifen-resistant breast cancer cells. The signaling pathway involves stimulation of the EGFR, a receptor tyrosine kinase that responds to binding of the extracellular ligand by dimerization, trans-phosphorylation and tyrosine kinase activation. EGFR is also transactivated by the protein tyrosine kinase Src, and this transactivation is stimulated by zinc. It is unclear where the zinc that stimulates Src activates originates, but it may involve a plasma membrane ZIP transporter. EGFR activation results in phosphorylation of ZIP7 by the serine/threonine protein kinase CK2, although it is unclear how the signal is transduced from EGFR to CK2. Phosphorylated ZIP7 transports zinc from the Golgi or ER into the cytoplasm. The increased cytoplasmic zinc inhibits protein tyrosine phosphatases (PTP), causing sustained activation of EGFR and Src. In addition, the released zinc activates kinases ERK1, ERK2 and Akt, which regulate signaling pathways leading to cancer cell proliferation and migration.

with metastatic breast cancer and $40 \%$ of patients receiving tamoxifen as an adjuvant therapy experience cancer relapse due to acquired tamoxifen resistance (TamR). ${ }^{178}$ An association between TamR and zinc dyshomeostasis has been identified (Figure 3). ${ }^{179}$ Compared to tamoxifen-sensitive cells, TamR breast cancer cells have twice the level of intracellular zinc and show increased mRNA and protein expression levels of the LIV-1 zinc transporter, ZIP7. ${ }^{179}$ The increased intracellular zinc is a direct result of the ZIP7 protein, as a decrease in zinc was observed in TamR cells in which ZIP7 was silenced. ${ }^{179}$ ZIP7, which localizes to the Golgi and ER membranes, is activated by protein kinase CK2 through phosphorylation of serine residues located in the large cytosolic loop of the transporter. ${ }^{98}$ The CK2 stimulation of ZIP7 occurs within minutes after exposure to an extracellular stimulus, suggesting that ZIP7 generates a zinc wave that is transduced to 'early' zinc signaling pathways in TamR breast cancer cells. ${ }^{98}$ In TamR cells, zinc stimulates MAPKs (ERK1 and ERK2) and Akt, indicating the involvement of ZIP7-mediated zinc transport in intracellular signaling pathways that affect cell proliferation, cell migration and apoptosis. ${ }^{98,179}$

Similarly, zinc activates the ERK and Akt kinase signaling pathways in breast cancer cells modeling HER2 overexpression tumors. $^{180}$ In the HER2 overexpression cells, ERK and Akt activation arise from a zinc-dependent stimulation of the $G$ protein-coupled estrogen receptor (GPER). Following stimulation, GPER transactivates the receptor tyrosine kinase epidermal growth factor receptor (EGFR). EGFR phosphorylation leads to downstream signaling that stimulates the kinases Erk1, Erk2 and Akt. Phosphorylated Erk1, Erk2 and Akt are translocated to the nucleus where they regulate the transcription of genes involved in cell proliferation, cell cycle progression and migration. The involvement of zinc as a signal for the GPER pathway may have prognostic effects. Higher GPER expression has been linked to poor survival in HER2-positive breast cancer cases. ${ }^{181,182}$

\section{CONCLUSION}

Recently, zinc has been recognized as a critical signaling molecule in normal cell physiology as well as in pathophysiological conditions, such as cancer. Under normal conditions, zinc has been shown to regulate several phosphorylation-dependent signaling cascades, including MAPKs and Akt, that play important roles in cell development, proliferation and cell death. Many of these same signaling cascades have been shown to be affected by zinc levels in cancer and lead to cancer cell proliferation and metastasis. Zinc signaling is controlled by cellular zinc homeostatic mechanisms that regulate intracellular zinc concentrations, especially the two zinc transporter families ZIP and ZnT. Not surprisingly, altered expression of these transporters is evident in many cancers. As a deeper understanding of the relationship between zinc transporter expression and downstream signaling pathways in tumors is gained, it may become possible to utilize zinc transporter profiles to tailor cancer treatments more effectively.

The complex interplay between zinc transporters and zinc signaling is just beginning to be deciphered. More structural studies on mammalian ZnT and, more importantly, on mammalian ZIP proteins are needed to clarify better the roles of metal transporters in cellular zinc homeostasis. One area that remains unclear is how the zinc signal is relayed from the transporter to the signaling pathways, many of which also involve membrane receptors. As very little free zinc exists in the cell, one area that needs exploration is the identification of protein-protein interactions that may be involved in the zinc relay. A detailed understanding of cellular zinc homeostasis and signaling is not only vital to understanding the role of zinc in normal cellular processes, but may also uncover new targets for cancer drug development.

\section{ACKNOWLEDGEMENTS}

The Dempski lab acknowledges support from the NIH (R01GM105964).

\section{COMPETING INTERESTS}

The authors declare no conflict of interest. 


\section{REFERENCES}

1 Krężel A, Maret W. The biological inorganic chemistry of zinc ions. Arch Biochem Biophys 2016; 611: 3-19.

2 Prasad AS, Halsted JA, Nadimi M. Syndrome of iron deficiency anemia, hepatosplenomegaly, hypogonadism, dwarfism and geophagia. Am J Med 1961; 31: 532-546.

3 Raulin J Études Chimiques Sur la Végétation. Masson \& Cie. 1905.

4 Brown KH, Rivera JA, Bhutta Z, Gibson RS, King JC, Lonnerdal B et al. International Zinc Nutrition Consultative Group (IZiNCG) technical document \#1. Assessment of the risk of zinc deficiency in populations and options for its control. Food Nutr Bull 2004; 25: S99-S203.

5 Prasad AS. Discovery of human zinc deficiency: its impact on human health and disease. Adv Nutr 2013; 4: 176-190.

6 Roohani N, Hurrell R, Kelishadi R, Schulin R. Zinc and its importance for human health: an integrative review. J Res Med Sci 2013; 18: 144-157.

7 Chasapis CT, Loutsidou AC, Spiliopoulou CA, Stefanidou ME. Zinc and human health: an update. Arch Toxicol 2012; 86: 521-534.

8 Kambe T, Hashimoto A, Fujimoto S. Current understanding of ZIP and ZnT zinc transporters in human health and diseases. Cell Mol Life Sci 2014; 71: 3281-3295.

9 Lipscomb WN, Strater N. Recent advances in zinc enzymology. Chem Rev 1996; 96: $2375-2434$

10 Keilin D, Mann T. Carbonic anhydrase. Nature 1939; 144: 442-443.

11 Andreini C, Banci L, Bertini I, Rosato A. Counting the zinc-proteins encoded in the human genome. J Proteome Res 2006; 5: 196-201.

12 Liang X, Dempski RE, Burdette SC. Zn 2+ at a cellular crossroads. Curr Opin Chem Biol 2016; 31: 120-125.

13 King JC, Shames DM, Woodhouse LR. Zinc homeostasis in humans. J Nutr 2000; 130: $1360 s-1366 s$

14 Krezel A, Maret W. Zinc-buffering capacity of a eukaryotic cell at physiological pZn. J Biol Inorg Chem 2006; 11: 1049-1062.

15 Costello LC, Fenselau CC, Franklin RB. Evidence for operation of the direct zinc ligand exchange mechanism for trafficking, transport, and reactivity of zinc in mammalian cells. J Inorg Biochem 2011; 105: 589-599.

16 Maret W. Zinc biochemistry: from a single zinc enzyme to a key element of life. Adv Nutr 2013; 4: 82-91.

17 Yuan N, Wang Y-h, Li K-j, Zhao Y, Hu X, Mao L et al. Effects of exogenous zinc on the cellular zinc distribution and cell cycle of A549 cells. Biosci Biotechnol Biochem 2012; 76: 2014-2020.

18 Haase H, Beyersmann D. Intracellular zinc distribution and transport in C6 rat glioma cells. Biochem Biophys Res Commun 2002; 296: 923-928.

19 Lu Q, Haragopal H, Slepchenko KG, Stork C, Li YV. Intracellular zinc distribution in mitochondria, ER and the Golgi apparatus. Int J Physiol Pathophysiol Pharmacol 2016; 8: 35-43.

20 Matsuyama S, Shimura M, Mimura H, Fujii $M$, Yumoto $H$, Sano $Y$ et al. Trace element mapping of a single cell using a hard $x$-ray nanobeam focused by a Kirkpatrick-Baez mirror system. $X$ Ray Spectrom 2009; 38: 89-94.

21 Kashiv Y, Austin JR II, Lai B, Rose V, Vogt S, El-Muayed M. Imaging trace element distributions in single organelles and subcellular features. Sci Rep 2016; 6: 21437.

22 Palmiter RD, Findley SD. Cloning and functional characterization of a mammalian zinc transporter that confers resistance to zinc. EMBO J 1995; 14: 639-649.

23 Lopez V, Kelleher SL. Zinc transporter-2 (ZnT2) variants are localized to distinct subcellular compartments and functionally transport zinc. Biochem J 2009; 422: 43-52.

24 Guo L, Lichten LA, Ryu M-S, Liuzzi JP, Wang F, Cousins RJ. STAT5-glucocorticoid receptor interaction and MTF-1 regulate the expression of ZnT2 (Slc30a2) in pancreatic acinar cells. Proc Natl Acad Sci USA 2010; 107: 2818-2823.

25 Kirschke CP, Huang L. Expression of the ZNT (SLC30) family members in the epithelium of the mouse prostate during sexual maturation. J Mol Histol 2008; 39: 359-370.

26 Ranaldi G, Perozzi G, Truong-Tran A, Zalewski P, Murgia C. Intracellular distribution of labile $\mathrm{Zn}$ (II) and zinc transporter expression in kidney and MDCK cells. Am J Physiol Renal Physiol 2002; 283: F1365-F1375.

27 Leung KW, Liu M, Xu X, Seiler MJ, Barnstable CJ, Tombran-Tink J. Expression of $\mathrm{ZnT}$ and ZIP zinc transporters in the human RPE and their regulation by neurotrophic factors. Invest Ophthalmol Vis Sci 2008; 49: 1221-1231.

28 Palmiter RD, Cole TB, Quaife CJ, Findley SD. ZnT-3, a putative transporter of zinc into synaptic vesicles. Proc Natl Acad Sci USA 1996; 93: 14934-14939.

29 Gyulkhandanyan AV, Lu H, Lee SC, Bhattacharjee A, Wijesekara N, Fox JE et al. Investigation of transport mechanisms and regulation of intracellular $\mathrm{Zn} 2+$ in pancreatic alpha-cells. J Biol Chem 2008; 283: 10184-10197.

30 Wenzel HJ, Cole TB, Born DE, Schwartzkroin PA, Palmiter RD. Ultrastructural localization of zinc transporter-3 (ZnT-3) to synaptic vesicle membranes within mossy fiber boutons in the hippocampus of mouse and monkey. Proc Natl Acad Sci USA 1997; 94: 12676-12681.
31 McCormick NH, Kelleher SL. ZnT4 provides zinc to zinc-dependent proteins in the trans-Golgi network critical for cell function and $\mathrm{Zn}$ export in mammary epithelial cells. Am J Physiol Cell Physiol 2012; 303: C291-C297.

32 Asano N, Kondoh M, Ebihara C, Fujii M, Nakanishi T, Soares MJ et al. Expression profiles of zinc transporters in rodent placental models. Toxicol Lett 2004; 154: 45-53.

33 Huang L, Gitschier J. A novel gene involved in zinc transport is deficient in the lethal milk mouse. Nat Genet 1997; 17: 292-297.

34 Smith JL, Xiong S, Markesbery WR, Lovell MA. Altered expression of zinc transporters- 4 and -6 in mild cognitive impairment, early and late Alzheimer's disease brain. Neuroscience 2006; 140: 879-888.

35 Inoue K, Matsuda K, Itoh M, Kawaguchi H, Tomoike H, Aoyagi T et al. Osteopenia and male-specific sudden cardiac death in mice lacking a zinc transporter gene, Znt5. Hum Mol Genet 2002; 11: 1775-1784.

36 Jackson KA, Helston RM, McKay JA, O'Neill ED, Mathers JC, Ford D. Splice variants of the human zinc transporter ZnT5 (SLC30A5) are differentially localized and regulated by zinc through transcription and mRNA stability. J Biol Chem 2007; 282: 10423-10431.

37 Huang L, Kirschke CP, Gitschier J. Functional characterization of a novel mammalian zinc transporter, ZnT6. J Biol Chem 2002; 277: 26389-26395.

38 Kirschke CP, Huang L. ZnT7, a novel mammalian zinc transporter, accumulates zinc in the Golgi apparatus. J Biol Chem 2003; 278: 4096-4102.

39 Chimienti F, Devergnas S, Favier A, Seve M. Identification and cloning of a beta-cell-specific zinc transporter, ZnT-8, localized into insulin secretory granules. Diabetes 2004; 53: 2330-2337.

40 Murgia C, Devirgiliis C, Mancini E, Donadel G, Zalewski P, Perozzi G. Diabeteslinked zinc transporter ZnT8 is a homodimeric protein expressed by distinct rodent endocrine cell types in the pancreas and other glands. Nutr Metab Cardiovasc Dis 2009; 19: 431-439.

41 Perez Y, Shorer Z, Liani-Leibson K, Chabosseau P, Kadir R, Volodarsky M et al. SLC30A9 mutation affecting intracellular zinc homeostasis causes a novel cerebro-renal syndrome. Brain 2017; 140: 928-939.

42 Bosomworth HJ, Thornton JK, Coneyworth LJ, Ford D, Valentine RA. Efflux function, tissue-specific expression and intracellular trafficking of the $\mathrm{Zn}$ transporter ZnT10 indicate roles in adult Zn homeostasis. Metallomics 2012; 4 771-779.

43 Andrews GK, Wang H, Dey S, Palmiter RD. Mouse zinc transporter 1 gene provides an essential function during early embryonic development. Genesis 2004; 40: 74-81.

44 Franklin RB, Ma J, Zou J, Guan Z, Kukoyi BI, Feng P et al. Human ZIP1 is a major zinc uptake transporter for the accumulation of zinc in prostate cells. J Inorg Biochem 2003; 96: 435-442.

45 Lioumi M, Ferguson CA, Sharpe PT, Freeman T, Marenholz I, Mischke D et al. Isolation and characterization of human and mouse ZIRTL, a member of the IRT1 family of transporters, mapping within the epidermal differentiation complex. Genomics 1999; 62: 272-280.

46 Gaither LA, Eide DJ. The human ZIP1 transporter mediates zinc uptake in human K562 erythroleukemia cells. J Biol Chem 2001; 276: 22258-22264.

47 Milon B, Dhermy D, Pountney D, Bourgeois M, Beaumont C. Differential subcellular localization of hZip1 in adherent and non-adherent cells. FEBS Lett 2001; 507: 241-246.

48 Gaither LA, Eide DJ. Functional expression of the human hZIP2 zinc transporter. $J$ Biol Chem 2000; 275: 5560-5564.

49 Cao J, Bobo JA, Liuzzi JP, Cousins RJ. Effects of intracellular zinc depletion on metallothionein and ZIP2 transporter expression and apoptosis. J Leukoc Biol 2001; 70: 559-566.

50 Gaither LA, Eide DJ. Eukaryotic Zinc Transporters and Their Regulation. Zinc Biochemistry, Physiology, and Homeostasis. Springer: Cham, Switzerland, 2001, pp 65-84.

51 Peters JL, Dufner-Beattie J, Xu W, Geiser J, Lahner B, Salt DE et al. Targeting of the mouse SIc39a2 (Zip2) gene reveals highly cell-specific patterns of expression, and unique functions in zinc, iron, and calcium homeostasis. Genesis 2007; 45: 339-352.

52 Costello LC, Zou J, Desouki MM, Franklin RB. Evidence for changes in RREB-1, ZIP3, and zinc in the early development of pancreatic adenocarcinoma. $J$ Gastrointest Cancer 2012; 43: 570-578.

53 Dufner-Beattie J, Huang ZL, Geiser J, Xu W, Andrews GK. Generation and characterization of mice lacking the zinc uptake transporter ZIP3. Mol Cell Biol 2005; 25: 5607-5615.

54 Dufner-Beattie J, Langmade SJ, Wang F, Eide D, Andrews GK. Structure, function, and regulation of a subfamily of mouse zinc transporter genes. J Biol Chem 2003; 278: 50142-50150.

55 Wang K, Zhou B, Kuo Y-M, Zemansky J, Gitschier J. A novel member of a zinc transporter family is defective in acrodermatitis enteropathica. Am J Hum Genet 2002; 71: 66-73. 
56 Wang F, Kim B-E, Petris MJ, Eide DJ. The mammalian Zip5 protein is a zinc transporter that localizes to the basolateral surface of polarized cells. J Biol Chem 2004; 279: 51433-51441.

57 Croxford TP, McCormick NH, Kelleher SL. Moderate zinc deficiency reduces testicular Zip6 and Zip10 abundance and impairs spermatogenesis in mice. J Nutr 2011; 141: 359-365.

58 Liu Y, Batchuluun B, Ho L, Zhu D, Prentice KJ, Bhattacharjee A et al. Characterization of zinc influx transporters (ZIPs) in pancreatic beta cells: roles in regulating cytosolic zinc homeostasis and insulin secretion. J Biol Chem 2015; 290: 18757-18769.

59 Huang L, Kirschke CP, Zhang Y, Yu YY. The ZIP7 gene (Slc39a7) encodes a zinc transporter involved in zinc homeostasis of the Golgi apparatus. J Biol Chem 2005; 280: 15456-15463.

60 Hogstrand C, Kille P, Nicholson RI, Taylor KM. Zinc transporters and cancer: a potential role for ZIP7 as a hub for tyrosine kinase activation. Trends Mol Med 2009; 15: 101-111.

61 Begum NA, Kobayashi M, Moriwaki Y, Matsumoto M, Toyoshima K, Seya T. Mycobacterium bovis BCG cell wall and lipopolysaccharide induce a novel gene, BIGM103, encoding a 7-TM protein: identification of a new protein family having Zn-transporter and Zn-metalloprotease signatures. Genomics 2002; 80: 630-645.

62 Ryu MS, Lichten LA, Liuzzi JP, Cousins RJ. Zinc transporters ZnT1 (SIc30a1), Zip8 (SIc39a8), and Zip10 (Slc39a10) in mouse red blood cells are differentially regulated during erythroid development and by dietary zinc deficiency. $J$ Nutr 2008; 138: 2076-2083.

63 Wang L, McDonnell SK, Hebbring SJ, Cunningham JM St, Sauver J, Cerhan JR et al. Polymorphisms in mitochondrial genes and prostate cancer risk. Cancer Epidemiol Biomarkers Prev 2008; 17: 3558-3566.

64 Matsuura W, Yamazaki T, Yamaguchi-Iwai Y, Masuda S, Nagao M, Andrews GK et al. SLC39A9 (ZIP9) regulates zinc homeostasis in the secretory pathway: characterization of the ZIP subfamily I protein in vertebrate cells. Biosci Biotechnol Biochem 2009; 73: 1142-1148.

65 Pawan K, Neeraj S, Sandeep K, Kanta Ratho R, Rajendra P. Upregulation of Slc39a10 gene expression in response to thyroid hormones in intestine and kidney. Biochim Biophys Acta 2007; 1769: 117-123.

66 Kagara N, Tanaka N, Noguchi S, Hirano T. Zinc and its transporter ZIP10 are involved in invasive behavior of breast cancer cells. Cancer Sci 2007; 98: 692-697.

67 Kaler P, Prasad R. Molecular cloning and functional characterization of novel zinc transporter rZip10 (Slc39a10) involved in zinc uptake across rat renal brushborder membrane. Am J Physiol Renal Physiol 2007; 292: F217-F229.

68 Kelleher SL, Velasquez V, Croxford TP, McCormick NH, Lopez V, MacDavid J. Mapping the zinc-transporting system in mammary cells: molecular analysis reveals a phenotype-dependent zinc-transporting network during lactation. J Cell Physiol 2012; 227: 1761-1770.

69 Yu Y, Wu A, Zhang Z, Yan G, Zhang F, Zhang L et al. Characterization of the GufA subfamily member SLC39A11/Zip11 as a zinc transporter. J Nutr Biochem 2013; 24: 1697-1708.

70 Chowanadisai W, Graham DM, Keen CL, Rucker RB, Messerli MA. Neurulation and neurite extension require the zinc transporter ZIP12 (slc39a12). Proc Natl Acad Sci USA 2013; 110: 9903-9908.

71 Zhao L, Oliver E, Maratou K, Atanur SS, Dubois OD, Cotroneo E et al. The zinc transporter ZIP12 regulates the pulmonary vascular response to chronic hypoxia. Nature 2015; 524: 356-360.

72 Fukada T, Civic N, Furuichi T, Shimoda S, Mishima K, Higashiyama H et al. The zinc transporter SLC39A13/ZIP13 is required for connective tissue development; its involvement in BMP/TGF-beta signaling pathways. PLOS ONE 2008; 3: e3642.

73 Bin B-H, Fukada T, Hosaka T, Yamasaki S, Ohashi W, Hojyo S et al. Biochemical characterization of human ZIP13 protein a homo-dimerized zinc transporter involved in the spondylocheiro dysplastic ehlers-danlos syndrome. $J$ Biol Chem 2011; 286: 40255-40265.

74 Nomura N, Miyajima N, Sazuka T, Tanaka A, Kawarabayasi Y, Sato S et al. Prediction of the coding sequences of unidentified human genes. I. The coding sequences of 40 new genes (KIAA0001-KIAA0040) deduced by analysis of randomly sampled cDNA clones from human immature myeloid cell line KG-1. DNA Res 1994; 1: 27-35.

75 Liuzzi JP, Aydemir F, Nam H, Knutson MD, Cousins RJ. Zip14 (Slc39a14) mediates non-transferrin-bound iron uptake into cells. Proc Natl Acad Sci USA 2006; 103: 13612-13617.

76 Zhao N, Gao J, Enns CA, Knutson MD. ZRT/IRT-like protein 14 (ZIP14) promotes the cellular assimilation of iron from transferrin. J Biol Chem 2010; 285: 32141-32150.

77 Lu M, Fu D. Structure of the zinc transporter YiiP. Science 2007; 317: 1746-1748.

$78 \mathrm{Lu} \mathrm{M}$, Chai J, Fu D. Structural basis for autoregulation of the zinc transporter YiiP. Nat Struct Mol Biol 2009; 16: 1063-1067.
79 Coudray N, Valvo S, Hu M, Lasala R, Kim C, Vink M et al. Inward-facing conformation of the zinc transporter YiiP revealed by cryoelectron microscopy. Proc Natl Acad Sci USA 2013; 110: 2140-2145.

80 Antala S, Ovchinnikov S, Kamisetty H, Baker D, Dempski RE. Computation and functional studies provide a model for the structure of the zinc transporter hZIP4. J Biol Chem 2015; 290: 17796-17805.

81 Zhang T, Sui D, Hu J. Structural insights of ZIP4 extracellular domain critical for optimal zinc transport. Nat Commun 2016; 7: 11979.

82 Bafaro EM, Antala S, Nguyen TV, Dzul SP, Doyon B, Stemmler TL et al. The large intracellular loop of hZIP4 is an intrinsically disordered zinc binding domain. Metallomics 2015; 7: 1319-1330.

83 Wei Y, Fu D. Selective metal binding to a membrane-embedded aspartate in the Escherichia coli metal transporter YiiP (FieF). J Biol Chem 2005; 280: 33716-33724.

84 Hoch E, Lin W, Chai J, Hershfinkel M, Fu D, Sekler I. Histidine pairing at the metal transport site of mammalian ZnT transporters controls $\mathrm{Zn} 2+$ over $\mathrm{Cd} 2+$ selectivity. Proc Natl Acad Sci USA 2012; 109: 7202-7207.

85 Gupta S, Chai J, Cheng J, D'Mello R, Chance MR, Fu D. Visualizing the kinetic power stroke that drives proton-coupled zinc (II) transport. Nature 2014; 512: 101-104.

86 Ohana E, Hoch E, Keasar C, Kambe T, Yifrach O, Hershfinkel M et al. Identification of the $\mathrm{Zn2}+$ binding site and mode of operation of a mammalian $\mathrm{Zn} 2+$ transporter. J Biol Chem 2009; 284: 17677-17686.

87 Shusterman E, Beharier O, Shiri L, Zarivach R, Etzion Y, Campbell CR et al. ZnT-1 extrudes zinc from mammalian cells functioning as a $\mathrm{Zn} 2+/ \mathrm{H}+$ exchanger. Metallomics 2014; 6: 1656-1663.

88 Zogzas CE, Aschner M, Mukhopadhyay S. Structural elements in the transmembrane and cytoplasmic domains of the metal transporter SLC30A10 are required for its manganese efflux activity. J Biol Chem 2016; 291: 15940-15957.

89 Salazar G, Falcon-Perez JM, Harrison R, Faundez V. SLC30A3 (ZnT3) oligomerization by dityrosine bonds regulates its subcellular localization and metal transport capacity. PLOS ONE 2009; 4: e5896.

90 Lasry I, Golan Y, Berman B, Amram N, Glaser F, Assaraf YG. In situ dimerization of multiple wild type and mutant zinc transporters in live cells using bimolecular fluorescence complementation. J Biol Chem 2014; 289: 7275-7292.

91 Golan Y, Berman B, Assaraf YG. Heterodimerization, altered subcellular localization, and function of multiple zinc transporters in viable cells using bimolecular fluorescence complementation. J Biol Chem 2015; 290: 9050-9063.

92 Fukunaka A, Suzuki T, Kurokawa Y, Yamazaki T, Fujiwara N, Ishihara K et al. Demonstration and characterization of the heterodimerization of ZnT5 and ZnT6 in the early secretory pathway. J Biol Chem 2009; 284: 30798-30806.

93 O'Halloran TV, Culotta VC. Metallochaperones, an intracellular shuttle service for metal ions. J Biol Chem 2000; 275: 25057-25060.

94 Antala S, Dempski RE. The human ZIP4 transporter has two distinct binding affinities and mediates transport of multiple transition metals. Biochemistry 2012; 51: 963-973.

$95 \mathrm{He} \mathrm{L}$, Girijashanker K, Dalton TP, Reed J, Li H, Soleimani M et al. ZIP8, member of the solute-carrier-39 (SLC39) metal-transporter family: characterization of transporter properties. Mol Pharmacol 2006; 70: 171-180.

96 Girijashanker K, He L, Soleimani M, Reed JM, Li H, Liu Z et al. Slc39a14 gene encodes ZIP14, a metal/bicarbonate symporter: similarities to the ZIP8 transporter. Mol Pharmacol 2008; 73: 1413-1423.

97 Colvin RA, Fontaine CP, Thomas D, Hirano T, Nagano T, Kikuchi K. Evidence for $\mathrm{pH}$ dependent Zn 2+ influx in K562 erythroleukemia cells: studies using ZnAF-2F fluorescence and $65 \mathrm{Zn}$ 2+ uptake. Arch Biochem Biophys 2005; 442: 222-228.

98 Taylor KM, Hiscox S, Nicholson Rl, Hogstrand C, Kille P. Protein kinase CK2 triggers cytosolic zinc signaling pathways by phosphorylation of zinc channel ZIP7. Sci Signal 2012; 5: ra11.

99 Lin W, Chai J, Love J, Fu D. Selective electrodiffusion of zinc ions in a Zrt-, Irt-like protein, ZIPB. J Biol Chem 2010; 285: 39013-39020.

100 Küry S, Dréno B, Bézieau S, Giraudet S, Kharfi M, Kamoun R et al. Identification of SLC39A4, a gene involved in acrodermatitis enteropathica. Nat Genet 2002; 31: 239-240.

101 Wang F, Kim B-E, Dufner-Beattie J, Petris MJ, Andrews G, Eide DJ. Acrodermatitis enteropathica mutations affect transport activity, localization and zincresponsive trafficking of the mouse ZIP4 zinc transporter. Hum Mol Genet 2004; 13: 563-571.

102 Kambe T, Andrews GK. Novel proteolytic processing of the ectodomain of the zinc transporter ZIP4 (SLC39A4) during zinc deficiency is inhibited by acrodermatitis enteropathica mutations. Mol Cell Biol 2009; 29: 129-139.

103 Schmitt S, Kury S, Giraud M, Dreno B, Kharfi M, Bezieau S. An update on mutations of the SLC39A4 gene in acrodermatitis enteropathica. Hum Mutat 2009; 30: 926-933.

104 Pocanschi CL, Ehsani S, Mehrabian M, Wille H, Reginold W, Trimble WS et al. The ZIP5 ectodomain co-localizes with PrP and may acquire a PrP-like fold that assembles into a dimer. PLOS ONE 2013; 8: e72446. 
105 Watts JC, Huo H, Bai Y, Ehsani S, Won AH, Shi T et al. Interactome analyses identify ties of PrP C and its mammalian paralogs to oligomannosidic N-glycans and endoplasmic reticulum-derived chaperones. PLoS Pathog 2009; 5: e1000608.

106 Schmitt-Ulms G, Ehsani S, Watts JC, Westaway D, Wille H. Evolutionary descent of prion genes from the ZIP family of metal ion transporters. PLOS ONE 2009; 4: e7208.

107 Taylor KM, Morgan HE, Smart K, Zahari NM, Pumford S, Ellis IO et al. The emerging role of the LIV-1 subfamily of zinc transporters in breast cancer. Mol Med 2007; 13: 396-406.

108 Franz M-C, Simonin A, Graeter S, Hediger MA, Kovacs G. Development of the first fluorescence screening assay for the SLC39A2 zinc transporter. J Biomol Screen 2014; 19: 909-916.

109 Taylor KM, Muraina IA, Brethour D, Schmitt-Ulms G, Nimmanon T, Ziliotto S et al. Zinc transporter ZIP10 forms a heteromer with ZIP6 which regulates embryonic development and cell migration. Biochem J 2016; 473: 2531-2544.

110 Kim B-E, Wang F, Dufner-Beattie J, Andrews GK, Eide DJ, Petris MJ. Zn2+-stimulated endocytosis of the MZIP4 zinc transporter regulates its location at the plasma membrane. J Biol Chem 2004; 279: 4523-4530.

111 Mao X, Kim B-E, Wang F, Eide DJ, Petris MJ. A histidine-rich cluster mediates the ubiquitination and degradation of the human zinc transporter, hZIP4, and protects against zinc cytotoxicity. J Biol Chem 2007; 282: 6992-7000.

112 Oldfield CJ, Dunker AK. Intrinsically disordered proteins and intrinsically disordered protein regions. Annu Rev Biochem 2014; 83: 553-584.

113 Wright PE, Dyson HJ. Intrinsically disordered proteins in cellular signalling and regulation. Nat Rev Mol Cell Biol 2015; 16: 18-29.

114 Brown CJ, Johnson AK, Dunker AK, Daughdrill GW. Evolution and disorder. Curr Opin Struct Biol 2011; 21: 441-446.

115 Giedroc DP, Chen X, Apuy JL. Metal response element (MRE)-binding transcription factor-1 (MTF-1): structure, function, and regulation. Antioxid Redox Signal 2001; 3: 577-596.

116 Kimura T, Itoh N, Andrews GK. Mechanisms of heavy metal sensing by metal response element-binding transcription factor-1. J Health Sci 2009; 55: 484-494.

117 Hardyman J, Tyson J, Jackson K, Aldridge C, Cockell S, Wakeling L et al. Zinc sensing by metal-responsive transcription factor 1 (MTF1) controls metallothionein and ZnT1 expression to buffer the sensitivity of the transcriptome response to zinc. Metallomics 2016; 8: 337-343.

118 Feng W, Cai J, Pierce WM, Franklin RB, Maret W, Benz FW et al. Metallothionein transfers zinc to mitochondrial aconitase through a direct interaction in mouse hearts. Biochem Biophys Res Commun 2005; 332: 853-858.

119 Mason AZ, Perico N, Moeller R, Thrippleton K, Potter T, Lloyd D. Metal donation and apo-metalloenzyme activation by stable isotopically labeled metallothionein. Mar Environ Res 2004; 58: 371-375.

120 Pinter TB, Stillman MJ. The zinc balance: competitive zinc metalation of carbonic anhydrase and metallothionein 1A. Biochemistry 2014; 53: 6276-6285.

121 Brautigan D, Bornstein P, Gallis B. Phosphotyrosyl-protein phosphatase. Specific inhibition by Zn. J Biol Chem 1981; 256: 6519-6522.

122 Klug A. The discovery of zinc fingers and their applications in gene regulation and genome manipulation. Annu Rev Biochem 2010; 79: 213-231.

123 Yamasaki S, Sakata-Sogawa K, Hasegawa A, Suzuki T, Kabu K, Sato E et al. Zinc is a novel intracellular second messenger. J Cell Biol 2007; 177: 637-645.

$124 \mathrm{Kim}$ EK, Choi E-J. Pathological roles of MAPK signaling pathways in human diseases. Biochim Biophys Acta Mol Basis Dis 2010; 1802: 396-405.

125 Stoker AW. Protein tyrosine phosphatases and signalling. J Endocrinol 2005; 185: 19-33.

126 Wilson M, Hogstrand C, Maret W. Picomolar concentrations of free zinc (II) ions regulate receptor protein-tyrosine phosphatase $\beta$ activity. J Biol Chem 2012; 287: 9322-9326.

127 Haase H, Ober-Blöbaum JL, Engelhardt G, Hebel S, Heit A, Heine H et al. Zinc signals are essential for lipopolysaccharide-induced signal transduction in monocytes. J Immunol 2008; 181: 6491-6502.

128 Hirano T, Murakami M, Fukada T, Nishida K, Yamasaki S, Suzuki T. Roles of zinc and zinc signaling in immunity: zinc as an intracellular signaling molecule. Adv Immunol 2008; 97: 149-176.

129 Yamashita S, Miyagi C, Fukada T, Kagara N, Che Y-S, Hirano T. Zinc transporter LIVI controls epithelial-mesenchymal transition in zebrafish gastrula organizer. Nature 2004; 429: 298-302.

130 Wang Y, Shi J, Chai K, Ying X, Zhou BP. The role of snail in EMT and tumorigenesis. Curr Cancer Drug Targets 2013; 13: 963-972.

131 Qian L, Lopez V, Seo YA, Kelleher SL. Prolactin regulates ZNT2 expression through the JAK2/STAT5 signaling pathway in mammary cells. Am J Physiol Cell Physiol 2009; 297: C369-C377.

132 Hojyo S, Fukada T, Shimoda S, Ohashi W, Bin B-H, Koseki $\mathrm{H}$ et al. The zinc transporter SLC39A14/ZIP14 controls G-protein coupled receptor-mediated signaling required for systemic growth. PLOS ONE 2011; 6: e18059.
133 Supasai S, Aimo L, Adamo A, Mackenzie G, Oteiza P. Zinc deficiency affects the STAT1/3 signaling pathways in part through redox-mediated mechanisms. Redox Biol 2017; 11: 469-481.

134 Mitchell TJ, John S. Signal transducer and activator of transcription (STAT) signalling and T-cell lymphomas. Immunol 2005; 114: 301-312.

135 Lee S, Hennigar SR, Alam S, Nishida K, Kelleher SL. Essential role for zinc transporter 2 (ZnT2)-mediated zinc transport in mammary gland development and function during lactation. J Biol Chem 2015; 290: 13064-13078.

136 Gumulec J, Masarik M, Adam V, Eckschlager T, Provaznik I, Kizek R. Serum and tissue zinc in epithelial malignancies: a meta-analysis. PLoS ONE 2014; 9: e99790.

137 Geiser J, De Lisle RC, Andrews GK. The zinc transporter Zip5 (SIc39a5) regulates intestinal zinc excretion and protects the pancreas against zinc toxicity. PLoS ONE 2013; 8: e82149.

138 Li M, Zhang Y, Liu Z, Bharadwaj U, Wang H, Wang X et al. Aberrant expression of zinc transporter ZIP4 (SLC39A4) significantly contributes to human pancreatic cancer pathogenesis and progression. Proc Natl Acad Sci USA 2007; 104: 18636-18641.

139 Dufner-Beattie J, Kuo Y-M, Gitschier J, Andrews GK. The adaptive response to dietary zinc in mice involves the differential cellular localization and zinc regulation of the zinc transporters ZIP4 and ZIP5. J Biol Chem 2004; 279: 49082-49090.

140 Costello LC, Levy BA, Desouki MM, Zou J, Bagasra O, Johnson LA et al. Decreased zinc and downregulation of ZIP3 zinc uptake transporter in the development of pancreatic adenocarcinoma. Cancer Biol Ther 2011; 12: 297-303.

141 Yang J, Zhang Y, Cui X, Yao W, Yu X, Cen P et al. Gene profile identifies zinc transporters differentially expressed in normal human organs and human pancreatic cancer. Curr Mol Med 2013; 13: 401-409.

142 Chandler P, Kochupurakkal BS, Alam S, Richardson AL, Soybel DI, Kelleher SL. Subtype-specific accumulation of intracellular zinc pools is associated with the malignant phenotype in breast cancer. Mol Cancer 2016; 15: 2.

143 Lener MR, Scott RJ, Wiechowska-Kozłowska A, Serrano-Fernández P, Baszuk P, Jaworska-Bieniek $\mathrm{K}$ et al. Serum concentrations of selenium and copper in patients diagnosed with pancreatic cancer. Cancer Res Treat 2016; 48: 1056-1064.

144 Manousos O, Trichopoulos D, Koutselinis A, Papadimitriou C, Polychronopoulou A, Zavitsanos X. Epidemiologic characteristics and trace elements in pancreatic cancer in Greece. Cancer Detect Prev 1981; 4: 439-442.

145 Ishida S, Andreux P, Poitry-Yamate C, Auwerx J, Hanahan D. Bioavailable copper modulates oxidative phosphorylation and growth of tumors. Proc Natl Acad Sci USA 2013; 110: 19507-19512.

146 Wang J, Luo C, Shan C, You Q, Lu J, Elf S et al. Inhibition of human copper trafficking by a small molecule significantly attenuates cancer cell proliferation. Nat Chem 2015; 7: 968-979.

147 Costello LC, Franklin RB. A comprehensive review of the role of zinc in normal prostate function and metabolism; and its implications in prostate cancer. Arch Biochem Biophys 2016; 611: 100-112.

148 Huang L, Kirschke CP, Zhang Y. Decreased intracellular zinc in human tumorigenic prostate epithelial cells: a possible role in prostate cancer progression. Cancer Cell Int 2006; 6: 10.

149 Desouki MM, Geradts J, Milon B, Franklin RB, Costello LC. hZip2 and hZip3 zinc transporters are down regulated in human prostate adenocarcinomatous glands. Mol Cancer 2007; 6: 37

150 Costello LC, Franklin RB. The clinical relevance of the metabolism of prostate cancer; zinc and tumor suppression: connecting the dots. Mol Cancer 2006; 5: 17.

151 Franklin RB, Feng P, Milon B, Desouki MM, Singh KK, Kajdacsy-Balla A et al. hZIP1 zinc uptake transporter down regulation and zinc depletion in prostate cancer. Mol Cancer 2005; 4: 32

152 Chen QG, Zhang Z, Yang Q, Shan GY, Yu XY, Kong CZ. The role of zinc transporter ZIP4 in prostate carcinoma. Urol Oncol 2012; 30: 906-911.

153 Hasumi M, Suzuki K, Matsui H, Koike H, Ito K, Yamanaka H. Regulation of metallothionein and zinc transporter expression in human prostate cancer cells and tissues. Cancer Lett 2003; 200: 187-195.

154 Albrecht AL, Somji S, Sens MA, Sens DA, Garrett SH. Zinc transporter mRNA expression in the RWPE-1 human prostate epithelial cell line. Biometals 2008; 21: 405-416.

155 Henshall SM, Afar DE, Rasiah KK, Horvath LG, Gish K, Caras I et al. Expression of the zinc transporter ZnT4 is decreased in the progression from early prostate disease to invasive prostate cancer. Oncogene 2003; 22: 6005-6012.

156 Franz $M-C$, Anderle $P$, Bürzle $M$, Suzuki $Y$, Freeman $M$, Hediger $M$ et al. Zinc transporters in prostate cancer. Mol Aspects Med 2013; 34: 735-741.

157 Singh CK, Malas KM, Tydrick C, Siddiqui IA, Iczkowski KA, Ahmad N. Analysis of zinc-exporters expression in prostate cancer. Sci Rep 2016; 6: 36772.

158 Han C-T, Schoene NW, Lei KY. Influence of zinc deficiency on Akt-Mdm2-p53 and Akt-p21 signaling axes in normal and malignant human prostate cells. Am J Physiol Cell Physiol 2009; 297: C1188-C1199. 
159 Bismar TA, Yoshimoto M, Vollmer RT, Duan Q, Firszt M, Corcos J et al. PTEN genomic deletion is an early event associated with ERG gene rearrangements in prostate cancer. BJU Int 2011; 107: 477-485.

160 Krohn A, Freudenthaler F, Harasimowicz S, Kluth M, Fuchs S, Burkhardt L et al. Heterogeneity and chronology of PTEN deletion and ERG fusion in prostate cancer. Mod Pathol 2014; 27: 1612-1620.

161 Lin M-C, Liu Y-C, Tam MF, Lu Y-J, Hsieh Y-T, Lin L-Y. PTEN interacts with metalresponsive transcription factor 1 and stimulates its transcriptional activity. Biochem J 2012; 441: 367-377.

162 Wei H, Desouki MM, Lin S, Xiao D, Franklin RB, Feng P. Differential expression of metallothioneins (MTs) 1, 2, and 3 in response to zinc treatment in human prostate normal and malignant cells and tissues. Mol Cancer 2008; 7: 7.

163 Han YC, Zheng ZL, Zuo ZH, Yu YP, Chen R, Tseng GC et al. Metallothionein $1 \mathrm{~h}$ tumour suppressor activity in prostate cancer is mediated by euchromatin methyltransferase 1. J Pathol 2013; 230: 184-193.

164 McCormick NH, Hennigar SR, Kiselyov K, Kelleher SL. The biology of zinc transport in mammary epithelial cells: implications for mammary gland development, lactation, and involution. J Mammary Gland Biol Neoplasia 2014; 19: 59-71.

165 Seo YA, Lopez V, Kelleher SL. A histidine-rich motif mediates mitochondrial localization of ZnT2 to modulate mitochondrial function. Am J Physiol Cell Physiol 2011; 300: C1479-C1489.

166 McCormick N, Velasquez V, Finney L, Vogt S, Kelleher SL. X-ray fluorescence microscopy reveals accumulation and secretion of discrete intracellular zinc pools in the lactating mouse mammary gland. PLOS ONE 2010; 5: e11078.

167 Chowanadisai W, Lonnerdal B, Kelleher SL. Identification of a mutation in SLC30A2 (ZnT-2) in women with low milk zinc concentration that results in transient neonatal zinc deficiency. J Biol Chem 2006; 281: 39699-39707.

168 Kelleher SL, Lopez V, Lönnerdal B, Dufner-Beattie J, Andrews GK. Zip3 (Slc39a3) functions in zinc reuptake from the alveolar lumen in lactating mammary gland. Am J Physiol Regul Integr Comp Physiol 2009; 297: R194-R201.

169 Falcón-Pérez JM, Dell'Angelica EC. Zinc transporter 2 (SLC30A2) can suppress the vesicular zinc defect of adaptor protein 3-depleted fibroblasts by promoting zinc accumulation in lysosomes. Exp Cell Res 2007; 313: 1473-1483.

170 Aydemir TB, Liuzzi JP, McClellan S, Cousins RJ. Zinc transporter ZIP8 (SLC39A8) and zinc influence IFN- $\gamma$ expression in activated human T cells. J Leukoc Biol 2009; 86: 337-348.

171 Rossi RE, Pericleous M, Mandair D, Whyand T, Caplin ME. The role of dietary factors in prevention and progression of breast cancer. Anticancer Res 2014; 34: 6861-6875.

172 Bostanci Z, Mack RP, Enomoto LM, Alam S, Brown A, Neumann C et al. Marginal zinc intake reduces the protective effect of lactation on mammary gland carcinogenesis in a DMBA-induced tumor model in mice. Oncol Rep 2016; 35: 1409-1416.
173 Geraki K, Farquharson M, Bradley D. Concentrations of Fe, Cu and Zn in breast tissue: a synchrotron XRF study. Phys Med Biol 2002; 47: 2327-2339.

174 Rongxianjin B-HB, Tan P-H, Tan BK-H. Metallothionein expression and zinc levels in invasive ductal breast carcinoma. Oncol Rep 1999; 6: 871-875.

175 Larner F, Woodley LN, Shousha S, Moyes A, Humphreys-Williams E, Strekopytov S et al. Zinc isotopic compositions of breast cancer tissue. Metallomics 2015; 7: $112-117$.

176 Riesop D, Hirner AV, Rusch P, Bankfalvi A. Zinc distribution within breast cancer tissue: a possible marker for histological grading? J Cancer Res Clin Oncol 2015; 141: 1321-1331.

177 Hogstrand C, Kille P, Ackland ML, Hiscox S, Taylor KM. A mechanism for epithelial-mesenchymal transition and anoikis resistance in breast cancer triggered by zinc channel ZIP6 and STAT3 (signal transducer and activator of transcription 3). Biochem J 2013; 455: 229-237.

178 Chang M-S. Tamoxifen resistance in breast cancer. Biomol Ther 2012; 20: 256-267.

179 Taylor KM, Vichova P, Jordan N, Hiscox S, Hendley R, Nicholson RI. ZIP7mediated intracellular zinc transport contributes to aberrant growth factor signaling in antihormone-resistant breast cancer Cells. Endocrinology 2008; 149: 4912-4920.

180 Pisano A, Santolla MF, De Francesco EM, De Marco P, Rigiracciolo DC, Perri MG et al. GPER, IGF-IR, and EGFR transduction signaling are involved in stimulatory effects of zinc in breast cancer cells and cancer-associated fibroblasts. Mol Carcinog 2017; 56: 580-593.

181 Sjöström M, Hartman L, Grabau D, Fornander T, Malmström P, Nordenskjöld B et al. Lack of $G$ protein-coupled estrogen receptor (GPER) in the plasma membrane is associated with excellent long-term prognosis in breast cancer. Breast Cancer Res Treat 2014; 145: 61-71.

182 Yang F, Shao Z-M. Double-edged role of G protein-coupled estrogen receptor 1 in breast cancer prognosis: an analysis of 167 breast cancer samples and online data sets. Onco Targets Ther 2016; 9: 6407-6415.

(c) (i) This work is licensed under a Creative Commons Attribution 4.0 International License. The images or other third party material in this article are included in the article's Creative Commons license, unless indicated otherwise in the credit line; if the material is not included under the Creative Commons license, users will need to obtain permission from the license holder to reproduce the material. To view a copy of this license, visit http://creativecommons.org/licenses/ by/4.0/

(c) The Author(s) 2017 